\title{
Disruption of Cdk5-Associated Phosphorylation of Residue Threonine-161 of the $\delta$-Opioid Receptor: Impaired Receptor Function and Attenuated Morphine Antinociceptive Tolerance
}

\author{
Wei-Yan Xie, ${ }^{\star}$ Yi He, ${ }^{*}$ Yan-Rui Yang, Ya-Fang Li, Kai Kang, Bao-Ming Xing, and Yun Wang \\ Neuroscience Research Institute and Department of Neurobiology, The Key Laboratory for Neuroscience of the Ministry of Education and Health, Peking \\ University Health Science Center, Beijing 100083, People's Republic of China
}

\begin{abstract}
Morphine is the most commonly used and most effective analgesic in the clinic. However, its use is limited by the tolerance. Evidence indicates that the $\delta$-opioid receptor (DOR) is essential for morphine antinociceptive tolerance; however, their underlying mechanisms are poorly understood. Here, we show that cyclin-dependent kinase 5 (Cdk5), activated in morphine antinociceptive tolerance, directly phosphorylates DOR at Thr-161 in DRG neurons. Cdk5 was found to phosphorylate Thr-161 in the second loop of DOR, but not the corresponding residue in the $\mu$-opioid receptor (MOR). Phosphorylation at Thr-161 is required for normal cell surface expression of DOR, and the formation of DOR-MOR heterodimers. Our studies indicated that inhibition of Cdk5 activity or overexpression of a DOR mutant lacking the Cdk5 phosphorylation site displayed relatively low cell surface expression and relatively low abilities to form heterodimers of DOR and MOR; intrathecal delivery of a construct expressing the T161A mutant of DOR attenuated morphine antinociceptive tolerance in rats, suggesting that Thr-161 phosphorylation of DOR contributed to Cdk5-mediated morphine antinociceptive tolerance. Furthermore, an engineered Tat fusion-interfering peptide corresponding to the second intracellular loop of DOR (Tat-DOR-2L), reduced the cell surface expression of DOR, disrupted the formation of DOR-MOR heterodimers, and significantly attenuated the development of morphine antinociceptive tolerance after intrathecal injection. The present study indicates that Cdk5-mediated phosphorylation of DOR at Thr-161 plays a crucial role in the development of morphine tolerance and suggests the possibility of targeting DOR phosphorylation at Thr-161 to attenuate morphine antinociceptive tolerance during pain management.
\end{abstract}

\section{Introduction}

Morphine is the most commonly used and most effective analgesic in the clinic. It works by activating three types of opioid receptors $(\mu, \delta$, and $\kappa)$. However, the use of morphine is limited by the morphine antinociceptive tolerance that accompanies its beneficial effects. The mechanisms of morphine antinociceptive tolerance are poorly understood because of the complexity of the underlying pathways. Although morphine acts primarily via $\mu$-opioid receptor (MOR) (Matthes et al., 1996), evidence indicates that $\delta$-opioid receptor (DOR) is also critical for the devel-

\footnotetext{
Received Jan. 26, 2009; accepted Feb. 9, 2009.

This work was supported by National Natural Science Foundation of China Grants 30371635, 303330026, 30770703, and 30830044; Beijing Natural Science Foundation Grant 7072040; and Specialized Research Fund for Doctoral Program of Higher Education Grant 20060001121. The EGFP-DOR-N3 construct was a generous gift from Prof. Rüdiger Schulz (University of Munich, Munich, Germany). The HA-tagged human $\mu$-opioid receptor construct was donated by Prof. Lee-Yuan Liu-Chen of Temple University School of Medicine (Philadelphia, PA). We thank Dr. Xu Zhang (Institute of Neuroscience and Key Laboratory of Neurobiology, Chinese Academy of Sciences, Shanghai, (hina) for helpful criticism of this manuscript.

${ }^{*} W .-Y . X$. and Y.H. contributed equally to this work.

Correspondence should be addressed to Prof. Yun Wang, Neuroscience Research Institute and Department of Neurobiology, Peking University, 38 Xueyuan Road, Beijing 100083, People's Republic of China. E-mail: wangy66@bjmu.edu.cn.

D01:10.1523/JNEUROSCI.0415-09.2009

Copyright $\odot 2009$ Society for Neuroscience $\quad$ 0270-6474/09/293551-14\$15.00/0
}

opment of morphine antinociceptive tolerance (Abdelhamid et al., 1991; Fundytus et al., 1995; Kest et al., 1996; Zhu et al., 1999). $\mathrm{DOR}^{-1-}$ mice have been shown not to exhibit morphine tolerance (Zhu et al., 1999; Nitsche et al., 2002). Activation of DOR appears to be an important intermediate step in the development of tolerance. Chronic morphine treatment upregulates DOR (Cahill et al., 2001; Morinville et al., 2003), and this leads to changes in MOR function. Similarly, protachykinin A gene knock-out mice (that leads to reduced cell surface insertion of DOR) do not develop morphine tolerance (Guan et al., 2005). All these results indicate that morphine tolerance requires the presence of functional DOR at the plasma membrane, and that MOR and DOR exhibit functional interaction (Rozenfeld et al., 2007). One mechanism for the role of DOR in modulating analgesia is through receptor heterodimerization; MOR-DOR heterodimerization has been shown to play an important role in the development of tolerance (Gomes et al., 2004; Rozenfeld et al., 2007).

Cdk5 is a unique member of the cyclin-dependent kinase (Cdk) family. The Cdk5/p35 complex is well known to play a pivotal role in the nervous system. In addition, Cdk5 activity has recently been shown to potentiate morphine tolerance (Pareek and Kulkarni, 2006). This result is consistent with our finding that the Cdk5 inhibitor roscovitine attenuated acute morphine 
antinociceptive tolerance (see Fig. 1A). Because Cdk5 has many substrates in the nervous system and is involved in many processes, investigating the specific target of Cdk5 action may help in the search for ways to manage morphine antinociceptive tolerance.

In the present study, we analyzed whether C $\mathrm{dk} 5$ phosphorylates DOR. Based on sequence analysis, we identified Thr-161, located in the second intracellular loop of DOR, as the only consensus phosphorylation site for $\mathrm{Cdk} 5$. We first performed in vitro phosphorylation analysis to verify that the second intracellular loop of DOR (DOR-2L) contains a Cdk5 phosphorylation site, and then we analyzed the activity of DOR proteins carrying mutations in this phosphorylation site, using both in vitro and in vivo experiments. Next, to investigate the role of the second intracellular loop of DOR, we designed and engineered Tat fusioninterfering peptide corresponding to the second intracellular loop of DOR (Tat-DOR-2L). We found that either knockdown of Cdk5 or Tat-DOR-2L reduced the cell surface expression of DOR and attenuated normal receptor function, and reduced the development of morphine antinociceptive tolerance in vivo. These results are the first to reveal a molecular mechanism for the functional regulation of morphine antinociceptive tolerance by Cdk5 through the phosphorylation of DOR at Thr-161. These findings provide new insights into drug development and new strategies for the control of morphine antinociceptive tolerance.

\section{Materials and Methods}

\section{Plasmid construction, mutation, and transfection}

Constructs to fuse glutathione $S$-transferase (GST) with the second intracellular loop of DOR (Asp145-Leu167) (GST-DOT-2L) were generated using terminal EcoRI/XhoI sites and subcloned into pGEX-5x-1 (GE Healthcare). The pEGFP-N3-DOR construct was a generous gift from Prof. Rüdiger Schulz (University of Munich, Munich, Germany) (Schulz et al., 2002). The construct expressing HA-tagged human $\mu$-opioid receptor was donated by Prof. Lee-Yuan Liu-Chen (Temple University School of Medicine, Philadelphia, PA). Mutants of DOR (GST-DORK164N, GST-MOR-2L, GST-DOR-L157F, DOR-T161A, and DORK164N) were created with the QuickChange site-directed mutagenesis kit (Stratagene). All constructs were confirmed by DNA sequencing (Shanghai Shenggong Bio).

Chemically synthesized RNA interference molecules for Cdk5 were purchased from Shanghai Genechem Company. The sequences used were as follows: CCAAGCUGCCAGACUAUAA. A nonsilencing RNA (UUCUCCGAACGUGUCACGU) duplex was used as a control.

Constructs were transiently transfected into $80 \%$ confluent NG108-15 cells or primary cultured dorsal root ganglion (DRG) neurons using Lipofectamine 2000 (Invitrogen) in serum-free DMEM. At $4 \mathrm{~h}$ after transfection, the medium was replaced with DMEM with $10 \%$ fetal bovine serum (FBS) (HyClone).

Tat-peptide construction

Tat-DOR-2L (RKKRRQRRRVKALDFRTPAKAKL), Tat-ctrl (RKKRRQRRRRAAKVPKFLTLDKA), and TAMRA-Tat-DOR-2L were synthesized and purified by the Chinese Peptide Company. The mass and purity of the peptide were verified by HPLC. Peptides were dissolved in $0.9 \%$ $\mathrm{NaCl}$ to a concentration of $10 \mu \mathrm{g} / \mu \mathrm{l}$.

\section{Cloning of Cdk5/DNCdk5 gene into a recombinant}

\section{adenovirus vector}

Cdk5/DNCdk5 gene was amplified by PCR from pEGFP-N1-Cdk5 and pEGFP-N1-DNCdk5 [the dominant-negative Cdk5 (N144) (Nikolic et al., 1996) was prepared by mutating an aspartic acid in the 144 position to an asparagine in the pEGFP-N1 Cdk5 plasmid], respectively, and then subcloned into pAdTrack vector, resulting in pAdTrack-CMV-Cdk5. The AdEasy system was used for generation of the recombinant adenovirus. The resultant pAdTrack-CMV-Cdk5 encoded a Cdk5 gene under the control of a cytomegalovirus (CMV) promoter followed by a green fluorescent protein (GFP) gene under the control of a second CMV promoter. This plasmid pAdTrack-CMV-Cdk5 was cotransformed into electrocompetent BJ5183 bacteria with pAdEasy-1 (containing the viral backbone) and selected on kanamycin LB plates. The complete adenovector was linearized and used for transfection of HEK293 cells, in which viral particles were further amplified, purified, and titered according to GFP-positive units.

\section{Generation of anti-DOR-phosphothreonine-161 antibody}

Anti-DOR-phosphothreonine-161 antibody (pDOR-Thr-161) was custom-made by 21 st Century Biochemicals. In brief, rabbits were immunized with the DOR-phosphothreonine peptide AcVKALDFR(pT)PAKAKLC-amide (sequence confirmed by MS Check; 21st Century Biochemicals) conjugated to keyhole limpet hemocyanin. Sera were obtained after five consecutive bleeds. To ensure the specificity of the antibody, sera obtained from immunized animals were subjected to multiple rounds of immunodepletion by passage through an affinity column of immobilized nonphosphopeptide antigen, followed by standard affinity purification using a column with the phosphopeptide antigen as ligand.

\section{Cell culture}

NG108-15 mouse neuroblastoma $\times$ rat glioma hybrid cells were cultured at $37^{\circ} \mathrm{C}$ in $60 \mathrm{~mm}$ dishes in a humidified atmosphere of $95 \%$ air and $5 \%$ $\mathrm{CO}_{2}$. The culture medium was DMEM with $10 \%$ FBS, HAT supplement (sodium hypoxanthine, aminopterin, and thymidine; Sigma-Aldrich), and $1 \mu \mathrm{M}$ 8-Br-cAMP (Sigma-Aldrich). HEK293 cells were cultured in DMEM with $10 \% \mathrm{FBS}$ at $37^{\circ} \mathrm{C}$ in $60 \mathrm{~mm}$ dishes in a humidified atmosphere of $95 \%$ air and $5 \% \mathrm{CO}_{2}$.

\section{Primary DRG culture}

Rats (3 weeks of age) were terminally anesthetized and decapitated. DRGs were removed one by one from all spinal segments and then digested with collagenase type IA $(1 \mathrm{mg} / \mathrm{ml}$; Sigma-Aldrich) and $0.25 \%$ trypsin (Sigma-Aldrich) for $30 \mathrm{~min}$ at $37^{\circ} \mathrm{C}$. After terminating the enzymatic treatment by addition of FBS, ganglia were dissociated with a Pasteur pipette, and the suspension of ganglia was sieved through a $70 \mu \mathrm{m}$ filter to remove debris and centrifuged at $500 \times g$ for $3 \mathrm{~min}$. The cell pellet was resuspended in Neurobasal growth medium supplemented with $2 \%$ B27, $100 \mathrm{ng} / \mathrm{ml}$ mouse nerve growth factor (Promega), $0.5 \mathrm{~mm}$ L-glutamine (Sigma-Aldrich), $2.5 \mu \mathrm{M}$ cytosine arabinoside (SigmaAldrich), $100 \mathrm{U} / \mathrm{ml}$ penicillin, and $100 \mu \mathrm{g} / \mathrm{ml}$ streptomycin. The resuspended cells were plated on $35 \mathrm{~mm}$ dishes coated with poly-D-lysine (100 $\mu \mathrm{g} / \mathrm{ml}$; Sigma-Aldrich) and kept for $5-8 \mathrm{~d}$ at $37^{\circ} \mathrm{C}$ in an incubator with $5 \% \mathrm{CO}_{2}$ and $95 \%$ air. On the second day and on alternate days after that, cells were fed with Neurobasal growth medium containing B27 supplement (Invitrogen).

\section{Cell surface biotinylation}

Primary cultured DRG neurons or NG108-15 cells were incubated in culture medium containing drugs for the indicated time periods, and then incubated with $500 \mu \mathrm{g} / \mathrm{ml}$ sulfo- $N$-hydroxysuccinimide-biotin (Pierce) in PBS for $45 \mathrm{~min}$ at $4^{\circ} \mathrm{C}$ to biotinylate surface proteins. After stopping the reaction, cells were lysed in buffer containing $0.1 \%$ Triton $\mathrm{X}-100,150 \mathrm{~mm} \mathrm{NaCl}, 25 \mathrm{~mm} \mathrm{KCl}, 10 \mathrm{~mm}$ Tris-HCl, pH 7.4, $1 \mu \mathrm{m}$ leupeptin, and $1 \mathrm{~mm}$ phenylmethylsulfonyl fluoride. Cell debris was removed by centrifugation at $12,000 \times g$ for $5 \mathrm{~min}$ at $4^{\circ} \mathrm{C}$. Biotinylated proteins were bound overnight at $4^{\circ} \mathrm{C}$ on immobilized NeutrAvidin protein (Pierce), and nonspecifically bound material was removed by washing six times in PBS containing $1 \%$ Triton X-100 and $0.1 \%$ SDS.

Washed beads were eluted with SDS sample buffer, and the eluate was resolved by SDS-PAGE and transferred to nitrocellulose membranes (Bio-Rad Laboratories). The membrane was blocked for $1 \mathrm{~h}$ with Trisbuffered saline (TBS) containing $0.05 \%$ Tween 20 and 5\% nonfat milk, and then probed GFP-tagged receptors by immunoblotting using an anti-GFP primary antibody (Santa Cruz Biotechnology) and a HRPconjugated secondary antibody (1:2000 dilution; goat anti-mouse; BioRad Laboratories). Finally, the blots were developed using the Western Blotting Luminol Reagent kit (Santa Cruz Biotechnology). 
$\mathrm{Ca}^{2+}$ imaging

To measure changes in intracellular free calcium, cells were incubated for $30 \mathrm{~min}$ at $37^{\circ} \mathrm{C}$ with the calcium-sensitive fluorescent probe fluo-3 $\mathrm{AM}$ $\left(\begin{array}{ll}10 & \mu \mathrm{M}\end{array}\right)$ (Invitrogen). The fluorometric recording chamber was mounted on a Leica TCS SP2 confocal microscope, and the probe was excited at $488 \mathrm{~nm}$. Data are expressed as change in fluorescence over baseline fluorescence $\left[\left(F-F_{0}\right) / F_{0}\right]$.

\section{Immunofluorescence}

After anesthesia, rats were perfused transcardially with $200 \mathrm{ml}$ of saline at $37^{\circ} \mathrm{C}$, followed by $200 \mathrm{ml}$ of ice-cold $4 \%$ paraformaldehyde in $0.1 \mathrm{M} \mathrm{PBS}$, $\mathrm{pH}$ 7.4. The L4/5 DRG were removed and postfixed in the same fixative agent for $2-4 \mathrm{~h}$, and then transferred to a $30 \%(\mathrm{v} / \mathrm{v})$ sucrose solution and incubated until the sample sank to the bottom of the container. Next, frozen tissue sections were cut coronally with a cryostat to a thickness of $6 \mu \mathrm{m}$. For detecting the in vivo delivery of genes and TAMRA-Tat-DOR2L, the DRG frozen sections were directly examined under a Leica fluorescence microscope.

\section{Immunoprecipitation}

Rat DRG lysates were immunoprecipitated at $4^{\circ} \mathrm{C}$ for $3 \mathrm{~h}$ using rabbit anti-DOR antibody or rabbit control IgG (Santa Cruz Biotechnology). Protein A-Sepharose CL-4B resin (GE Healthcare) was added to the samples, and the incubation was continued for an additional $12 \mathrm{~h}$ with or without Tat-DOR-2L/Tat-ctrl. The samples were then washed six times with TBS/0.1\% Triton X-100 to solubilize bound proteins. The washed pellet was boiled in SDS-PAGE sample buffer and analyzed by Western blot using mouse anti-Cdk5 antibody. IgG staining served as a loading control.

NG108-15 cells were lysed in lysis buffer ( $50 \mathrm{~mm}$ Tris, pH 7.4, $150 \mathrm{~mm}$ $\mathrm{NaCl}, 1.5 \mathrm{~mm} \mathrm{MgCl}_{2}, 10 \%$ glycerol, $1 \%$ Triton X-100, 5 mM EGTA, 0.5 $\mu \mathrm{g} / \mathrm{ml}$ leupeptin, $1 \mathrm{~mm}$ PMSF, $1 \mathrm{~mm} \mathrm{Na}_{3} \mathrm{VO}_{4}, 10 \mathrm{~mm} \mathrm{NaF}$, and proteinase inhibitor mixture). For immunoprecipitation, $400-500 \mu \mathrm{g}$ of protein was incubated overnight at $4^{\circ} \mathrm{C}$ with rabbit polyclonal anti-GFP antibody (Santa Cruz Biotechnology) with protein A-Sepharose CL-4B resin (GE Healthcare). The samples were then washed six times with TBS $/ 0.1 \%$ Triton X-100 to solubilize bound proteins. The proteins were resolved by $10 \%$ SDS-PAGE and analyzed by Western blot using monoclonal anti-HA antibody (Applygen Technologies).

Phosphoproteins were immunoprecipitated with mouse antiphosphothreonine antibody (H-2; Santa Cruz Biotechnology, CA) or control IgG (Santa Cruz Biotechnology). The extracts were then reabsorbed overnight at $4^{\circ} \mathrm{C}$ on protein A-Sepharose CL-4B resin (GE Healthcare), with rocking, after which the resin was washed six times. The agarose resin was recovered by centrifugation, and then resuspended in $20 \mu \mathrm{l}$ of SDS loading buffer. Samples were then analyzed by SDSPAGE and Western blotting using rabbit anti-GFP antibody (Santa Cruz Biotechnology).

\section{Phosphorylation assay}

Tissue lysates containing $500 \mu \mathrm{g}$ of protein of rat cortex extracts were diluted in lysis buffer to a volume of $500 \mu \mathrm{l}$ and then immunoprecipitated at $4^{\circ} \mathrm{C}$ for $3 \mathrm{~h}$ with anti-Cdk5 antibody (1:50; Santa Cruz Biotechnology). Protein A-Sepharose CL-4B resin was added to the samples, and the incubation was continued for another $12 \mathrm{~h}$. The samples were washed four times with TBS/0.1\% Triton X-100 and two times with assay buffer (20 mm Tris-HCl, pH 7.5, 20 mm $\mathrm{MgCl}_{2}, 1$ mm EDTA, 1 mm EGTA, and $0.1 \mathrm{~mm}$ dithiothreitol). The washed pellet was resuspended to a final volume of $40 \mu \mathrm{l}$ in reaction buffer containing $20 \mathrm{~mm}$ Tris- $\mathrm{HCl}, \mathrm{pH} 7.5,20$ mм $\mathrm{MgCl}_{2}, 1$ mм EDTA, 1 mм EGTA, $0.1 \mathrm{~mm}$ dithiothreitol, $0.2 \mu \mathrm{g} / \mu \mathrm{l}$ GST fusion protein, and $0.2 \mu \mathrm{Ci} / \mu \mathrm{l}\left[\gamma_{-}{ }^{32} \mathrm{P}\right] \mathrm{ATP}$ (or replaced by common ATP in cold phosphorylation assay). The mixture was incubated at $30^{\circ} \mathrm{C}$ for $30 \mathrm{~min}$, and the reaction was terminated by the addition of SDS-PAGE sample buffer. After boiling for $5 \mathrm{~min}$, the samples were subjected to SDS-PAGE. The gels were stained with Coomassie Brilliant Blue, dried, and exposed to $\mathrm{x}$-ray film for autoradiography.

\section{In vitro kinase assay}

Cdk5 kinase activity was measured as described previously using an immune complex kinase assay and histone $\mathrm{H} 1$ as substrate (Nikolic et al.,
1998). Briefly, tissue lysates were immunoprecipitated with anti-Cdk5 antibody $4^{\circ} \mathrm{C}$ for $3 \mathrm{~h}$. Protein A-Sepharose CL-4B resin (GE Healthcare) was added to the samples and incubation was continued for an additional $12 \mathrm{~h}$, after which samples were washed four times with TBS/ $0.1 \%$ Triton $\mathrm{X}-100$ and two times with assay buffer $(20 \mathrm{~mm}$ Tris- $\mathrm{HCl}, \mathrm{pH} 7.5,20 \mathrm{~mm}$ $\mathrm{MgCl}_{2}, 1 \mathrm{~mm}$ EDTA, 1 mм EGTA, and $0.1 \mathrm{~mm}$ dithiothreitol). The final pellet was resuspended in reactive buffer $[20 \mathrm{~mm}$ Tris- $\mathrm{HCl}, \mathrm{pH} 7.5,20$ mм $\mathrm{MgCl}_{2}, 1$ mм EDTA, 1 mM EGTA, $0.1 \mathrm{~mm}$ dithiothreitol, $0.08 \mu \mathrm{g} / \mu \mathrm{l}$ histone $\mathrm{H} 1$ protein (Sigma-Aldrich), $\left.0.2 \mu \mathrm{Ci} / \mu \mathrm{l}\left[\gamma_{-}{ }^{32} \mathrm{P}\right] \mathrm{ATP}\right]$ to yield a total volume of $40 \mu \mathrm{l}$. The mixture was incubated at $30^{\circ} \mathrm{C}$ for $30 \mathrm{~min}$, and the reaction was terminated by the addition of SDS-PAGE sample buffer. After boiling for $5 \mathrm{~min}$, the samples were subjected to SDS-PAGE. The gels were stained with Coomassie Brilliant Blue, dried, and exposed to $\mathrm{x}$-ray film for autoradiography.

\section{Animals and surgery}

Male Sprague Dawley rats (200-250 g) were obtained from the animal center of Peking University Health Science Center. Rats were housed in climate-controlled rooms on a $12 \mathrm{~h}$ light/dark cycle with ad libitum access to food and water. Animals were acclimated for $5 \mathrm{~d}$ before any experimental procedures began. All experimental procedures conformed to the guidelines of the Animal Care and Use Committee of Peking University. For intrathecal drug delivery, implantation of intrathecal cannulae was performed according to the method of Størkson et al. (1996). Briefly, rats weighing 200-220 g were anesthetized with $10 \%$ chloral hydrate $(0.3$ $\mathrm{g} / \mathrm{kg}$, i.p.). The back skin of the rats was incised and the spinal column was exposed. The intraspinal space between lumbar vertebrae 4 and 5 (L4 and L5) was chosen as the site for insertion of the needle. Slight movements of the tail indicated proper insertion of the needle into the subarachnoid space. PE-10 polyethylene catheters were implanted $4.0 \mathrm{~cm}$ using a catheter-through-needle technique to reach the lumbar enlargement of the spinal cord. The outer end of the catheter was plugged and fixed onto the skin on closure of the wound. The rats were allowed 5-6 d for recovery before being tested in all experiments. Animals with neurological damage after catheter implantation were excluded from the study. Nociceptive responses after intrathecal injection or delivery of genes were measured in a blinded manner.

\section{Delivery of genes into the DRG and the spinal dorsal horn}

After 4-5 d of recovery from the surgical placement of the intrathecal catheter, rats were subjected to intrathecal injection of one of the following constructs: pEGFP-N3-WT-DOR, pEGFP-N3-T161A-DOR, pEGFP-N3-K164N-DOR, and pEGFP-N1. The rats were randomized into the following experimental groups: normal saline (NS), pEGFP-N1, pEGFP-N3-WT-DOR, pEGFP-N3-T161A-DOR, and pEGFP-N3K164N-DOR. Complexes of $10 \mu \mathrm{g}$ of DNA and Lipofectamine 2000, prepared as described below, were injected slowly over $5 \mathrm{~min}$. After the injection, the needle was left in situ for 2 min before being withdrawn. The basal tail flick latency was measured $4 \mathrm{~d}$ after gene delivery, followed by an acute morphine tolerance test. DNA-Lipofectamine 2000 complexes were prepared as follows: DNA $(10 \mu \mathrm{g})$ was diluted in $10 \mu \mathrm{l}$ of NS and mixed gently. Lipofectamine $2000(20 \mu \mathrm{l})$ was added to $10 \mu \mathrm{l}$ of NS and mixed gently. After $5 \mathrm{~min}$ incubation at room temperature, the diluted DNA was combined with the diluted Lipofectamine 2000, mixed, and incubated for $20 \mathrm{~min}$ at room temperature to allow the DNA-Lipofectamine 2000 complexes to form. The mixture was then injected intrathecally as described. The ratio of DNA (in micrograms) to Lipofectamine 2000 (in microliters) was 1:2. The total volume injected was 40 $\mu l$.

\section{Drug administration}

After $4-5 \mathrm{~d}$ of recovery from the surgical placement of the intrathecal catheter, rats were subjected to one of the following treatment protocols. One group received intrathecal injection of the Cdk5 inhibitor roscovitine ( 10 or $100 \mu \mathrm{g}$; Sigma-Aldrich), followed by injection of $5 \mu \mathrm{l}$ of sterile normal saline administered $30 \mathrm{~min}$ before the first morphine challenge. Another group received intrathecal injection of Tat-DOR-2L/Tat-ctrl (3 $\mu \mathrm{g}$ ), followed by injection of $5 \mu \mathrm{l}$ of sterile normal saline, and then, 30 min later, injection with deltorphin I ( $10 \mu \mathrm{g}$ in $4 \mu \mathrm{l}$ of normal saline; GL Biochem). Behavioral tests were performed at 15, 30, 45, 60, 90, and 120 
min. A third group of rats received intrathecal injection of Tat-DOR-2L/ Tat-ctrl $(3 \mu \mathrm{g})$, followed by $5 \mu \mathrm{l}$ of sterilized normal saline, and then, 30 min later, an injection of DAMGO ( $1 \mathrm{nmol}$ in $4 \mu \mathrm{l}$ of normal saline; Sigma-Aldrich). Behavioral tests were then performed at 15, 30, 45, 60, 90, and $120 \mathrm{~min}$.

In the acute morphine antinociceptive tolerance experiment, rats were allowed to recover from catheter implantation like the other groups, and then they received an intrathecal injection of $4 \mu \mathrm{l}$ of Tat-DOR-2L (1, 3, and $10 \mu \mathrm{g})$ or Tat-ctrl $(10 \mu \mathrm{g})$, followed by $5 \mu \mathrm{l}$ of sterile saline $30 \mathrm{~min}$ before the first morphine challenge.

In the chronic morphine antinociceptive tolerance experiment, rats were allowed to recover from catheter implantation as above, and then they received an intrathecal injection of $4 \mu \mathrm{l}$ of Tat-DOR-2L $(0.3,1$, or 3 $\mu \mathrm{g})$ or Tat-ctrl $(3 \mu \mathrm{g})$, followed by $5 \mu \mathrm{l}$ of sterile saline $30 \mathrm{~min}$ before the first morphine challenge.

\section{Induction of morphine antinociceptive tolerance and} behavioral testing

Acute morphine antinociceptive tolerance. Rats received six consecutive injections of morphine at $2 \mathrm{~h}$ intervals $(5 \mathrm{mg} / \mathrm{kg}$, s.c.; Qinghai Pharmaceutical Factory). Nociception was assessed $30 \mathrm{~min}$ after each injection by the radiant heat tail flick assay, which is a standard index of morphine analgesia.

Chronic morphine antinociceptive tolerance. Morphine was injected subcutaneously twice a day (at 8:00 A.M. and 8:00 P.M.) for 5 d. Each dose of morphine was $5 \mathrm{mg} / \mathrm{kg}$ from day 1 to day 5 . The development of tolerance was detected every day at 8:00 P.M. by measuring tail flick latency $30 \mathrm{~min}$ after a challenge injection of morphine $(5 \mathrm{mg} / \mathrm{kg}$, s.c.).

Morphine antinociception was assessed $30 \mathrm{~min}$ after morphine treatment using the tail flick method (Prado, 2003). The routine tail flick test was done with baseline latencies of $4-6 s$ and a cutoff time of $15 \mathrm{~s}$ to avoid tissue damage. Three trials were done with an intertrial interval of $1 \mathrm{~min}$; the part of the tail receiving radiant heat stimulation was changed for each trial. The change in tail flick latency (TFL) was determined by comparing the tail flick latency before [baseline (BL)] and after drug injection (TL) using the following equation: \% Change in TFL = Min [(TL $\mathrm{BL}) / \mathrm{BL} \times 100,150]$. The maximal possible effect (MPE) was defined as follows: $[(\mathrm{TL}-\mathrm{BL}) /(15-\mathrm{BL}) \times 100 \%]$.

\section{Results \\ Inhibition of Cdk5 activity attenuates DOR-mediated calcium influx and decreases cell surface expression of DOR}

Activation of Cdk 5 has been reported to be involved in morphine tolerance (Pareek and Kulkarni, 2006). In the present study, we first investigated the effect of the Cdk5-specific inhibitor roscovitine on morphine antinociceptive tolerance. All rats were given morphine $(5 \mathrm{mg} / \mathrm{kg}$, s.c.) every $2 \mathrm{~h}$ for $12 \mathrm{~h}$ to induce acute antinociceptive tolerance to morphine analgesia. Roscovitine dissolved in DMSO was injected intrathecally in different doses (10 or $100 \mu \mathrm{g}$ ), $30 \mathrm{~min}$ before the first morphine treatment. Either dose of roscovitine significantly delayed the development of morphine antinociceptive tolerance compared with the vehicle (DMSO) control group (Fig. 1 A), suggesting that roscovitine can delay the development of acute morphine antinociceptive tolerance.

Although morphine acts primarily via MOR, considerable evidence indicates that morphine tolerance requires the presence of functional DOR at the plasma membrane, and chronic morphine treatment leads to increased DOR surface expression. Reducing cell surface insertion of DOR (such as preprotachykinin A gene knock-out) inhibits developing morphine tolerance (Guan et al., 2005). Does Cdk5 affect the bioavailability or physiological function of DOR by phosphorylating it? To answer this question, we examined whether inhibition of Cdk5 activity affects DOR function. First, we used a well established model of [D-Pen2,D-Pen5]enkephalin (DPDPE)-induced calcium release in NG108-15 cells (Jin et al., 1994; Smart and Lambert, 1996), NG108-15 cells as one type of nervous system-derived cell lines, we detected strong Cdk5 activity in it, and we tested the behavior of this model in the presence and absence of roscovitine (see supplemental material, available at www.jneurosci.org). Because NG108-15 cells endogenously express only DOR and not MOR, NG108-15 cells are often used as the model to study the function of endogenous DOR; thus, here we used DPDPE as the DOR agonist. Applying DPDPE to NG108-15 cells, which express abundant endogenous DOR, produced the expected rapid and sharp calcium increase: $28 \%$ of cells responded ( 23 of 85 cells), and this increase was significantly reduced in cells pretreated with roscovitine, only $3 \%$ of which responded ( 3 of 97 cells) (Fig. $1 B$ ). In summary, inhibiting Cdk5 activity attenuates DOR-mediated calcium influx.

After confirming the effect of the inhibition of Cdk5 activity on DOR-mediated calcium release, we examined whether inhibition of Cdk5 activity also affects the bioavailability of DOR. For this experiment, we used cell surface biotinylation to detect the cell surface expression of DOR. NG108-15 cells transfected with GFP-DOR were labeled with a membrane-impermeable biotinylation reagent, sulfo-NHS-biotin, and the biotinylated proteins were purified using immobilized streptavidin. The isolated proteins were then examined by Western blotting using an anti-GFP antibody. The cells treated with $30 \mu \mathrm{m}$ roscovitine for $4 \mathrm{~h}$ showed lower levels of DOR on the surface than did the control cells (Fig. $1 C)$. We confirmed this effect of roscovitine on the cell surface expression of DOR in cultured DRG neurons, and we also found that roscovitine did not affect endogenous MOR, indicating that Cdk5 does not interact with MOR directly (Fig. 1D). To test whether endogenous Cdk5 activity affects DOR cell surface expression, we infected cultured DRG neurons with adenovirus driving expression of GFP alone or GFP together with a kinasedead Cdk5 construct [DNCdk5, carrying an Asp-144-to-Asn mutation (Nikolic et al., 1996)] or the wild-type Cdk5. Overexpression of DNCdk5, but not wild-type Cdk5, decreased the cell surface expression of DOR relative to control cultures infected with GFP alone. The total extract shows the expression of Cdk5 with Cdk5 antibody (Fig. 1E).

The involvement of Cdk5 is further supported by studies using short interfering RNA (siRNA) targeting the Cdk5 mRNA in NG108-15 cells. We found a significant decrease in the surface levels of DOR in cells cotransfected with GFP-DOR and Cdk5 siRNA, compared with cells cotransfected with control siRNA. Analysis of total cell extracts indicated that Cdk5 had no observable effect on the total expression level of DOR protein (Fig. 1G). These results support the idea that endogenous Cdk5 acts as a crucial role in the cell surface expression of DOR.

\section{Cdk5 phosphorylates DOR at Thr-161 in the second intracellular loop, and Lys-164 is necessary for this phosphorylation of Cdk5 in vitro and in vivo}

After confirming the effects of the inhibition of Cdk5 on DOR cell surface expression, we next asked whether Cdk5 and DOR interact directly. As reported previously, both DOR (Zhang et al., 1998; Zhu et al., 1998) and Cdk5 (Pareek et al., 2006; Yang et al., 2007) are present in the cytoplasm of DRG neurons in vivo (data not shown). We immunoprecipitated DOR from rat DRG lysates and probed the immunoblots with an antibody against $\mathrm{Cdk} 5$. The Cdk5-specific antibody, but not control IgG, recognized a band with a molecular weight consistent with that of Cdk5, indicating a physical interaction between Cdk5 and DOR in rat DRG neurons (Fig. 2A).

Cdk5 is a proline-directed serine/threonine kinase. In addition to an absolute requirement for proline in the +1 position, 
A

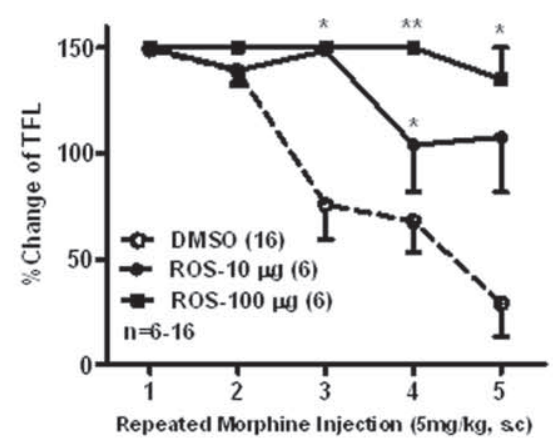

C

\section{Biotinylated}

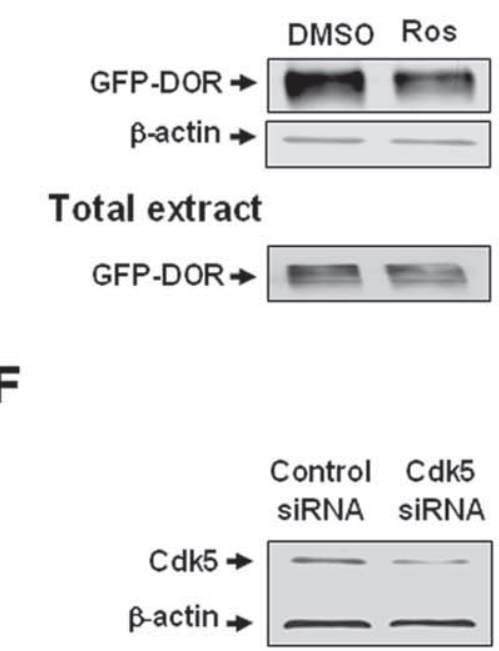

B
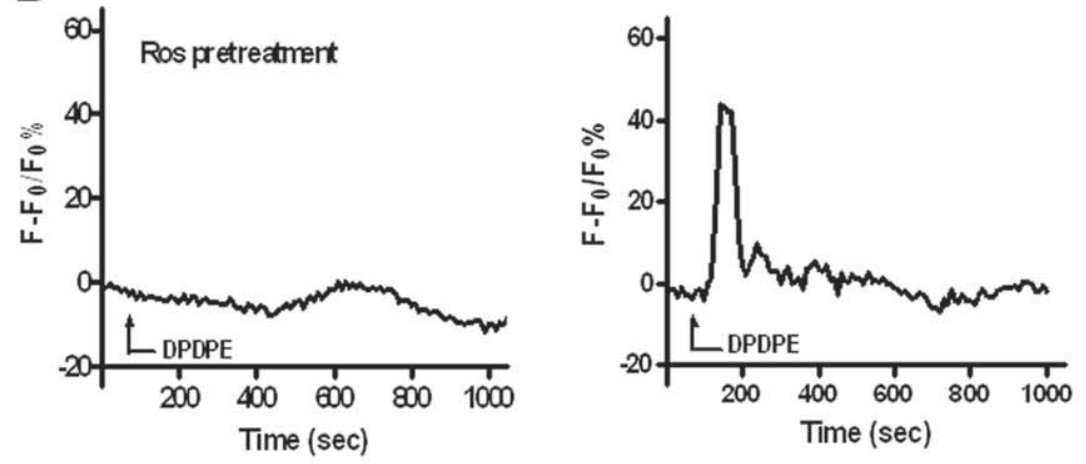

D

Biotinylated

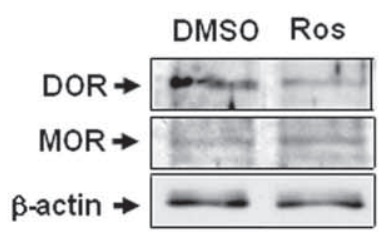

E

Biotinylated

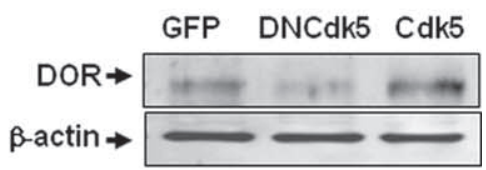

Total extract

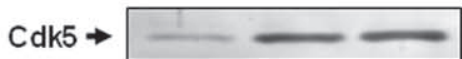

G

Biotinylated

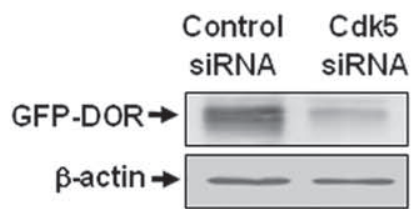

Total extract

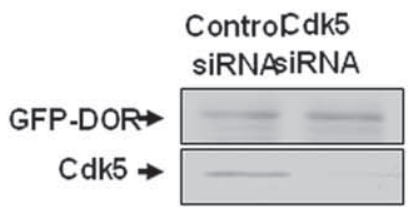

Figure 1. Inhibition of Cdk5 activity attenuates DOR-mediated calcium influx and decreases cell surface expression of DOR. $A$, Both groups receiving a single intrathecal injection of roscovitine (10 or $100 \mu \mathrm{g}$ ) showed significant delay in the development of morphine antinociceptive tolerance compared with the DMSO control group. ${ }^{* *} p<0.01,{ }^{*} p<0.05$, compared with the DMSO group. Error bars indicate SEM. $\boldsymbol{B}$, Representation of transient $\mathrm{Ca}^{2+}$ trace after DPDPE incubation with or without pretreatment with roscovitine ( $30 \mu \mathrm{m} ; 30 \mathrm{~min}$ ). Ros, Roscovitine. $\boldsymbol{C}-\boldsymbol{E}$, Surface-biotinylated DOR showed that inhibition of (dk5 significantly decreased the expression of functional DOR ( $\sim 90 \mathrm{kDa}$ ) at the cell surface. C, Pretreatment with roscovitine ( $30 \mu \mathrm{m}$; $4 \mathrm{~h}$ ) significantly decreased D0R cell surface expression in NG108-15 cells transfected with EGFP-DOR compared with DMSO control. Total extract represents the total expression level. $D$, Effect of roscovitine on cell surface expression of endogenous DOR and MOR in primary cultures of DRG neurons. Blots were reprobed with anti-actin antibody to ensure equal loading. $E$, Effect of $C d k 5$ on cell surface expression of endogenous DOR in primary cultures of DRG neurons infected with adenovirus driving expression of GFP alone or GFP together with a kinase-dead Cdk5 construct (DNCdk5) or the wild-type Cdk5 (Cdk5). The total extract shows the expression of Cdk5 with Cdk5 antibody. $F$, Representative Western blots of Cdk5 in NG108-15 cells transfected with control or specific C $\mathrm{dk5}$ siRNA. Blots were probed with anti-actin antibody to ensure equal transfer and loading. G, Effect of Cdk5 siRNA on cell surface expression of DOR in NG108-15 cells transfected with GFP-D0R. Total extract represents the total expression level. All the above data are representative of three independent experiments.

Cdk5 shows a marked preference for a basic residue in the +3 position. Its consensus phosphorylation sequence is (S/T) PX (K/H/R), where X can be any amino acid (Beaudette et al., 1993; Songyang et al., 1996). Figure $2 B$ provides a schematic representation of two opioid receptors, MOR and DOR, showing the single putative Cdk5 phosphorylation site in DOR (TPAK, located in the second intracellular loop) and the lack of Cdk5 phosphorylation sites in MOR.

Phosphorylation of opioid receptors is the key first step in their activation during such processes as desensitization and trafficking. In the absence of ligand, opioid receptors show a basal constitutive activity and agonist occupation induces a dramatic increase in receptor-stimulated G-protein turnover. To investigate the role of Cdk5 in DOR phosphorylation in vivo, proteins phosphorylated on threonine residues of NG108-15 cells coexpressing wild-type DOR and Cdk5 siRNA or control siRNA were immunoprecipitated with phosphospecific antibodies. DOR can be phosphorylated on serine, threonine, or tyrosine residues, and the putative Cdk5 phosphorylation site is at Thr-161; thus, we used the amount of phosphothreonine as the indicator of total activity of DOR. As shown in Figure 2C, transfection with Cdk5 siRNA attenuated the phosphorylation level of DOR, indicating that Cdk5 may contribute to the basal phosphorylation of DOR.

To examine whether Cdk5 can directly phosphorylate DOR and where, we generated four fusion proteins of GST and the following: the second intracellular loop of DOR (DOR-2L); a mutant of DOR-2L in which lysine 164 is replaced by asparagine (K164N), eliminating the putative phosphorylation motif for Cdk5; the second intracellular loop of MOR (MOR-2L); a L157F mutant to serve as a control for the site-directed mutagenesis. All four of these fusion proteins were tested for their ability to act as substrates of Cdk5 in an in vitro kinase assay (Fig. 2D). Cdk5 preferentially phosphorylated GST-DOR-2L, suggesting that this protein contained a much better Cdk5 phosphorylation site than the other proteins. In contrast, the phosphorylation levels of the GST-DOR-2L-K164N and GST-MOR-2L mutants were rela- 
A

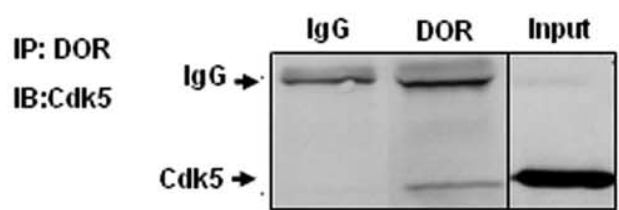

C

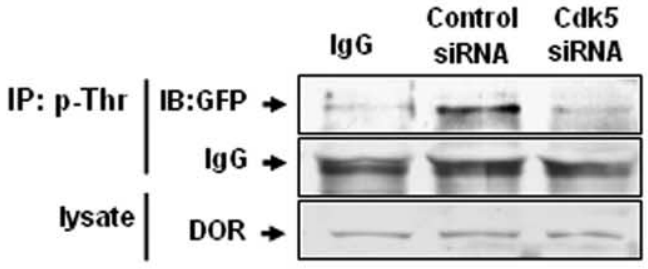

D

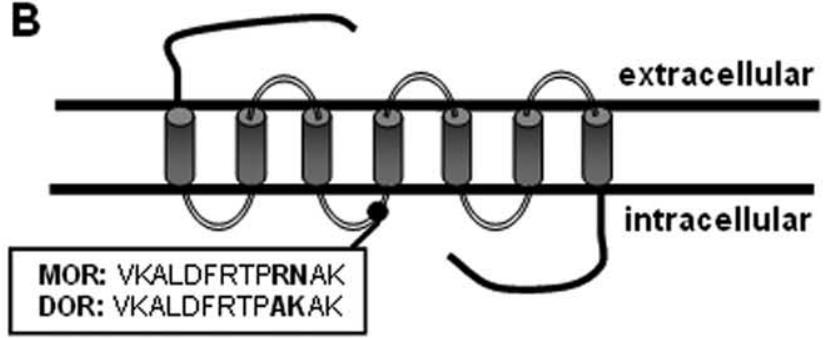

E

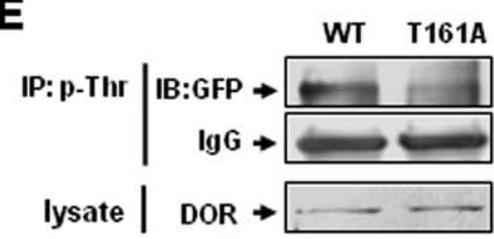

F

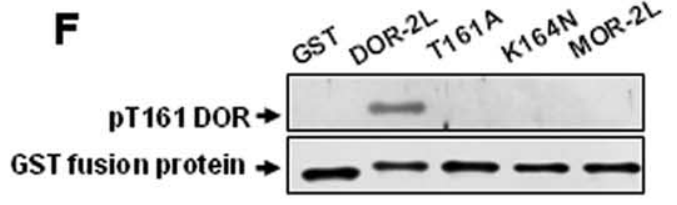

I

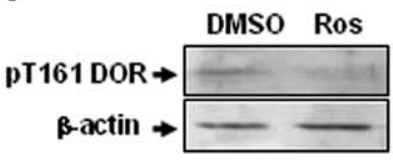

G

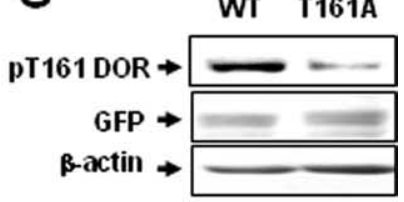

H

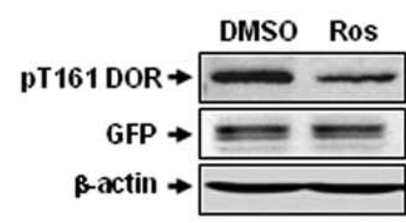

K

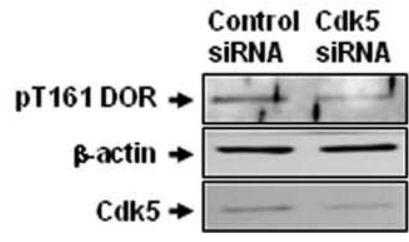

L

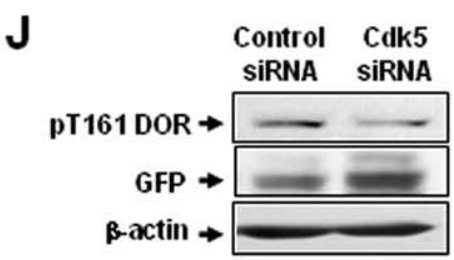

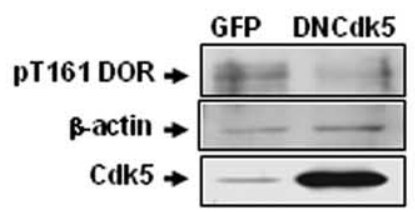

Figure 2. Cdk5 phosphorylates DOR directly at Thr- 161 in the second intracellular loop, and Lys-164 is necessary for this phosphorylation of Cdk5 in vitro and in vivo. A, Interaction of Cdk5 and DOR in rat DRGs. Cdk5-specific antibody recognized the complex immunoprecipitated (IP) by DOR-specific antibody, but normal lgG did not. $\boldsymbol{B}$, Schematic representation of two opioid receptors, MOR and DOR, showing the putative Cdk5 phosphorylation site (TPAK) in the second intracellular loop in DOR, but not in MOR. C, Representative Western blots of DOR proteins after immunoprecipitation with a phosphothreonine-specific antibody in cells cotransfected with EGFP-DOR and control siRNA or Cdk5 siRNA. IgG was used as negative controls. Results are representative of three independent experiments. D, Cdk5 phosphorylates DOR at Thr-161. Purified GST and GST fusion proteins were used as substrates for the Cdk5 kinase assays. Cdk5 was immunoprecipitated from rat brain lysates using a Cdk5-specific antibody. Autoradiographs are shown at the top, and corresponding Coomassie Blue-stained gel are shown at the bottom. GST-DOR-2L and GST-DOR-2L-L157F were phosphorylated by Cdk5, whereas GST-DOR-2L-K164N and GST-MOR-2L were not. E, Representative Western blots of DOR proteins after immunoprecipitation with a phosphothreonine-specific antibody in cells transfected with wild-type DOR or the T161A mutant. $F$, In Cdk5 cold kinase assay, purified GST and GST fusion proteins were immunodetected with pT161 DOR phosphoantibody, showing specificity of the pT161 DOR phosphoantibody for the wild-type GST-DOR-2L. G, NG108-15 cells were transfected with wild-type DOR and DOR mutant T161A, and the blots were immunodetected with site-specific PT161 DOR antibody. Total cell lysates were immunoblotted with GFP and actin antibodies as a loading control. $\boldsymbol{H}$, Cdk5 inhibitor roscovitine reduces DOR Thr- 161 phosphorylation. NG108-15 cells were transfected with GFP-DOR and treated for $4 \mathrm{~h}$ with the indicated drugs, and then immunoblotted with pT161 DOR antibody. Total cell lysates were immunoblotted with GFP and actin antibodies as loading controls. I, Effect of roscovitine on Thr- 161 phosphorylation of endogenous DOR in primary cultures of DRG neurons. Blots were reprobed with anti-actin antibody to ensure equal loading.J, Cdk5 siRNA reduces DOR Thr-161 phosphorylation. NG108-15 cells were cotransfected with GFP-DOR and control or specific Cdk5 siRNA, and then immunoblotted with pT161 DOR antibody. Total cell lysates were immunoblotted with GFP and actin antibodies as a loading control. $\boldsymbol{K}$, Effect of Cdk5 siRNA on Thr-161 phosphorylation of endogenous DOR in primary cultures of DRG neurons. Blots were reprobed with anti-actin antibody to ensure equal loading. $L$, Effect of Cdk5 on Thr-161 phosphorylation of endogenous DOR in primary cultures of DRG neurons infected with adenovirus driving expression of GFP alone or GFP together with DNCdk5.

tively low. In addition, $\mathrm{Cdk} 5$ retained its ability to phosphorylate GST-2L-L157F, confirming the sequence specificity of phosphorylation. Together, these results show that Thr-161 is the phosphorylation site of Cdk5 and that Lys-164 is necessary for this phosphorylation of Cdk5 in vitro. The data from the kinase assay also provide hints that $\mathrm{Cdk} 5$ may preferentially phosphorylate DOR compared with MOR.

To determine whether the residue Thr-161, the putative Cdk5 
A

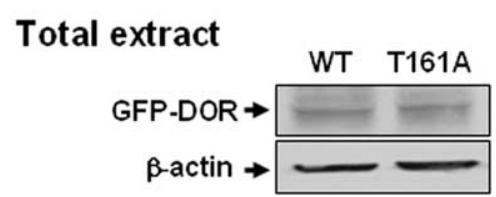

C

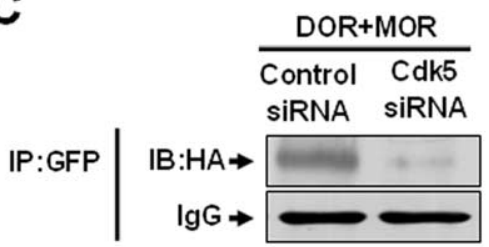

Lysate

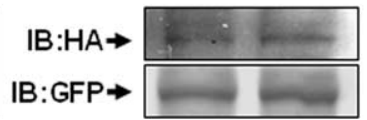

B

\section{Biotinylated}

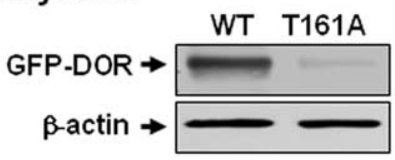

D

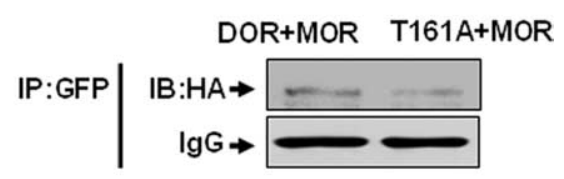

\begin{tabular}{l|l} 
Lysate & $\mathrm{IB}: \mathrm{HA} \rightarrow \square$ \\
& $\mathrm{IB}: \mathrm{GFP} \rightarrow$
\end{tabular}

Figure 3. Thr-161 is required for cell surface expression of DOR and the formation of DOR-MOR heterodimers. $A$, No significant changes in the total expression level between wild-type D0R (WT) and T161A-D0R after transient transfection in NG108-15 cells. $\boldsymbol{B}$, Surface-biotinylated DOR showed that the expression of functional DOR at the cell surface for the T161A mutant was significantly less than that of WT-DOR after transient transfection in NG108-15 cells. C, Cell lysates from NG108-15 cells cotransfected with EGFP-DOR $(2 \mu \mathrm{g})$, HA-MOR $(4 \mu \mathrm{g})$ CDNA, and Cdk5 siRNA or control siRNA were subjected to immunoprecipitation using polyclonal anti-GFP antibody. Associated HA-MOR was detected by immunoblotting using a monoclonal anti-HA antibody. The levels of DOR and MOR in each transfection are shown by immunoblotting with anti-GFP and anti-HA antibodies, respectively. $D$, Cell lysates from NG108-15 cells cotransfected with EGFP-DOR (wild type or T161A) $(2 \mu \mathrm{g})$ and HA-MOR $(4 \mu \mathrm{g})$ cDNA were subjected to immunoprecipitation using polyclonal anti-GFP antibody. Associated HA-MOR was detected by immunoblotting using a monoclonal anti-HA antibody. The levels of DOR and MOR in each transfection are shown by immunoblotting with anti-GFP and anti-HA antibodies, respectively. Results are representative of three independent experiments.

phosphorylation site of Cdk5, is necessary for the basal DOR phosphorylation, NG108-15 cells expressing the wild-type or T161A mutant receptor were immunoprecipitated with antiphosphothreonine antibodies. DOR was detected in the precipitates by Western blot analysis using an anti-GFP antibody. As shown in Figure $2 E$, the DOR phosphorylation level in cells expressing wild-type receptor was much higher than in cells expressing the T161A receptor mutant, indicating that Thr-161 phosphorylation is necessary for the basal phosphorylation of DOR. The results indicate that $\mathrm{Cdk} 5$ can phosphorylate DOR at Thr-161, and this phosphorylation contributes to the basal phosphorylation of DOR.

To study DOR phosphorylation on Thr-161 more directly, we raised phosphospecific antibodies against the pT161 phosphopeptide. We tested the ability of pT161 DOR-specific antibody to recognize GST fusion proteins; first, we treated GST fusion proteins with alkaline phosphatase, calf intestinal (CIP) for $2 \mathrm{~h}$, and then these GST fusion proteins were subjected to in vitro cold phosphorylation assay (common ATP replaced $\left[{ }^{32} \mathrm{P}\right]$ ATP) by Cdk5. The result of Figure $2 F$ clearly shows that GST alone and GST-DOR-2L mutant did not react with pT161 DOR antibody. Moreover, on Western blots, pT161 DOR phosphospecific antibody detected an expected $90 \mathrm{kDa}$ mass protein band from wild-type GFP-tagged DOR expressed in NG108-15 cells, but not GFP-DOR (T161A) (Fig. 2G). Collectively, these data indicate that pT161 DOR phosphoantibody specifically recognizes DOR phosphorylated on Thr-161. To test whether Cdk5 can phosphorylate Thr-161 of DOR in vivo, first, we applied the Cdk5 inhibitor roscovitine to NG108-15 cells overexpressing GFP-tagged DOR. We found that roscovitine ( $30 \mu \mathrm{M} ; 4 \mathrm{~h})$ signif- icantly decreased the pT161 DOR signal (Fig. $2 H$ ). We confirmed this effect of roscovitine on DOR phosphorylation in cultured primary DRG neurons (Fig. 2I). To confirm whether this effect was induced by Cdk5, we used Cdk5 siRNA to suppress expression of endogenous Cdk5 in NG108-15 cells. As showed in Figure $2 J$, similar results were obtained, in which one can see that reduced levels of cdk5 expression correlate with significantly decreased pT161 DOR signal. We also confirmed this effect of Cdk5 siRNA on DOR phosphorylation in cultured primary DRG neurons (Fig. $2 \mathrm{~K}$ ). To further confirm the role of Cdk5 in DOR phosphorylation in primary neuron, we infected cultured DRG neurons with adenovirus driving expression of GFP alone or GFP together with a DNCdk5. Overexpression of DNCdk5 decreased DOR Thr-161 phosphorylation relative to control cultures infected with GFP alone (Fig. 2L). These results show that DOR was phosphorylated by Cdk5 at Thr-161 in cell lines and DRG neurons.

\section{Thr-161 is required for cell surface} expression of DOR and the formation of DOR-MOR heterodimers

After confirming that Cdk5 phosphorylates DOR at Thr-161, we then investigated the function of DOR carrying a mutation at this residue. We measured the total expression of wild-type DOR (WT) and T161A DOR (T161A) in NG108-15 cells. NG108-15 cells were transfected with EGFP-WT-DOR or EGFP-T161A. Probing the blots with antiGFP antibody detected an immunoreactive band of $\sim 90 \mathrm{kDa}$ in both wild-type and mutant DOR-expressing cells (Fig. 3A), indicating that the T161A mutation did not cause obvious changes in the total expression level of DOR protein. Because the T161A mutant did not show an obvious change in the total protein level of DOR, we used cell surface biotinylation to detect the cell surface expression of DOR. Intact cells were labeled with a membrane-impermeable biotinylation reagent, sulfo-NHSbiotin, and the biotinylated proteins were purified using immobilized streptavidin. The receptor was then analyzed by Western blotting using the anti-GFP antibody in both DOR-expressing NG108-15 cells (Fig. 3B). Surprisingly, the cell surface biotinylation assay indicated that the expression of functional T161ADOR $(\sim 90 \mathrm{kDa})$ was significantly less than that of WT-DOR in both cell lines. The result that there was less expression of T161ADOR in cell surface by overexpressing T161A-DOR in NG108-15 was consistent with the result shown in Figure 1G: that knockdown of endogenous Cdk5 with Cdk5 siRNA decreases the amount of functional DOR at the cell surface.

Although morphine acts primarily via MOR, considerable evidence indicates that morphine antinociceptive tolerance requires the presence of functional DOR at the plasma membrane and that MOR and DOR functionally interact (Rozenfeld et al., 2007). The most likely model is that chronic morphine treatment leads to increased DOR surface expression, the DOR proteins form heterodimers with MOR, and these heterodimers recruit $\beta$-arrestin2, which leads to a switch in signaling and the activa- 
A

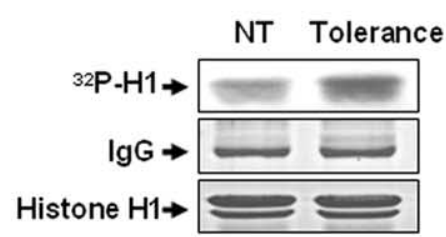

D
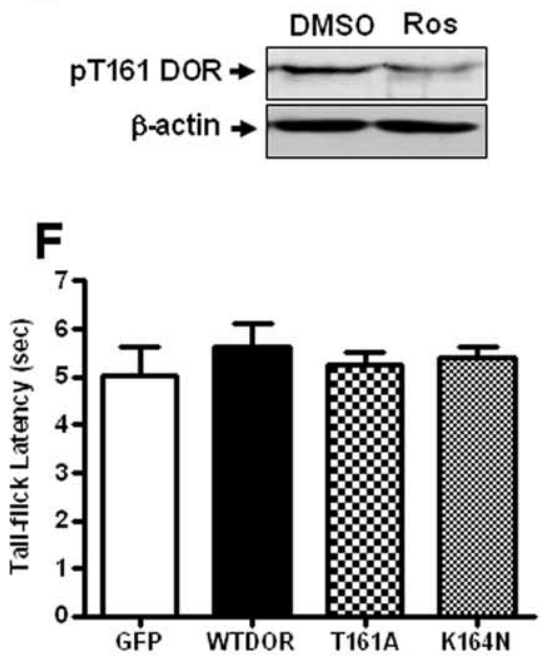

B
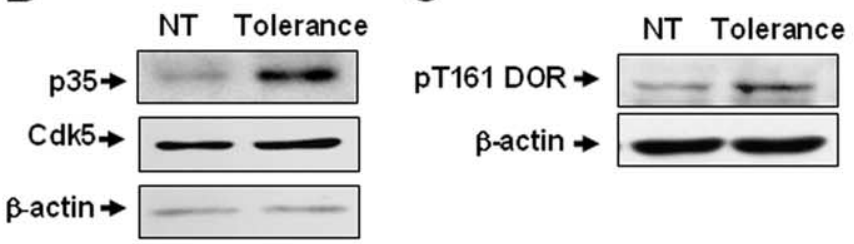

E
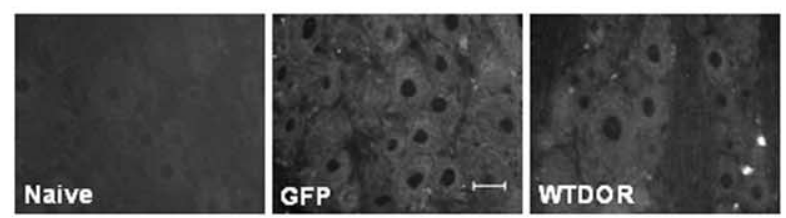

G

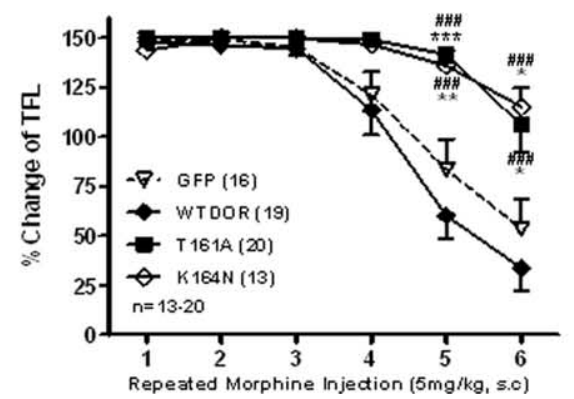

H

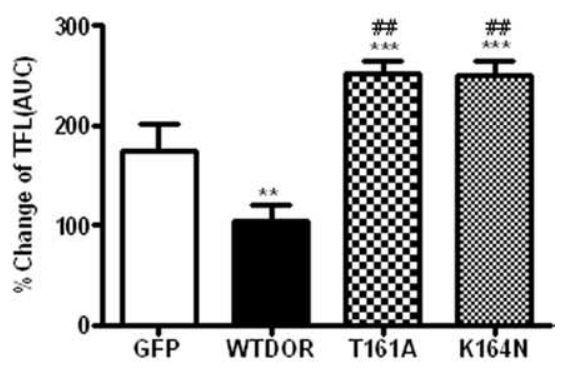

Figure 4. Cdk5 activity and Thr-161 phosphorylation of DOR are required for morphine antinociceptive tolerance. $\boldsymbol{A}$, Representative Cdk5 kinase activity of DRG protein isolated from untreated rats (NT) or rats treated with morphine repeatedly (Tolerance), detected by an in vitro phosphorylation assay. Histone H1 was used as a substrate. $\boldsymbol{B}$, Representative Western blot analysis of DRG protein isolated from rats treated with morphine repeatedly, blotted with $\mathrm{p} 35$ antibody. Total DRG lysates were immunoblotted with actin antibody as loading controls. $\boldsymbol{C}$, Representative Western blot analysis of DRG protein isolated from untreated rats (NT) or rats treated with morphine repeatedly (Tolerance), blotted with pT161 D0R antibody. Total DRG lysates were immunoblotted with actin antibody as loading controls. NT, Nontreatment. $\boldsymbol{D}$, Representative Western blot analysis of DRG protein isolated from rats treated with morphine repeatedly, pretreatment with DMSO or roscovitine, blotted with pT161 DOR antibody. Total DRG lysates were immunoblotted with actin antibody as loading controls. $\boldsymbol{E}$, Green fluorescent signal was observed by fluorescent microscopy in primary sensory neurons $5 \mathrm{~d}$ after delivery of the indicated constructs. Scale bar, $20 \mu \mathrm{m}$. $\boldsymbol{F}$, Exogenous expression of WT-D0R or the mutants T161A or K164N had no effect on basal nociceptive response in rats. G, The effect of intrathecal delivery of the indicated constructs on the development of morphine antinociceptive tolerance. Delivery of pEGFP-N3-T161A and pEGFP-N3-K164N resulted in markedly slower development of morphine antinociceptive tolerance compared with groups receiving pEGFP-N3-WT-DOR or pEGFP-N3 alone. The symbols represent means, and vertical lines represent SEM. ${ }^{*} p<0.05,{ }^{* *} p<0.01,{ }^{* * *} p<0.001$, compared with EGFP group; ${ }^{\# \#} p<0.001$, compared with WT-DOR group ( $\left.n=13-20\right)$. $\boldsymbol{H}$, The bar graphs are expressed as a percentage of maximal area under the curve (AUC), which was calculated from the fifth morphine injection to the sixth morphine injection. The columns refer to means \pm SEM. ${ }^{* *} p<0.001,{ }^{* *} p<0.01$, compared with EGFP group; ${ }^{\# \#} p<0.01$, compared with WT-DOR group $(n=13-20)$. All data were analyzed by ANOVA, followed by the Newman-Keuls multiple-comparison test.

tion of distinct downstream kinases and transcription factors (Rozenfeld and Devi, 2007). Thus, we investigated whether Cdk5 as well as Cdk5-mediated DOR phosphorylation affect the formation of DOR-MOR heterodimers. First, we cotransfected NG108-15 cells with Cdk5 siRNA; as expected, Cdk5 siRNA inhibited the formation of DOR-MOR heterodimers (Fig. 3C). Then, we cotransfected the cells with GFP-tagged wild-type DOR/T161A-DOR, and HA-tagged MOR, which shows that HAMOR coimmunoprecipitated with wild-type GFP-DOR, but the level of heterodimers was reduced when Thr-161 was mutated (Fig. 3D). These data suggest that Cdk5 may affect the formation of DOR-MOR heterodimers by phosphorylating DOR at Thr-161.

Cdk5 activity and Thr-161 phosphorylation of DOR are required for morphine antinociceptive tolerance in vivo To test whether morphine antinociceptive tolerance induces Cdk5 activation in DRG, we used an in vitro phosphorylation assay and found that Cdk5 activity was relatively low in normal rats and increased markedly after morphine treatment. The his- tone $\mathrm{H} 1$ and IgG protein level, determined by staining with Coomassie Brilliant Blue, was used as loading control (Fig. 4A).p35 is the most important Cdk5 activator and is required for Cdk5 kinase activity (Tsai et al., 1994); thus, we investigated p35 and Cdk5 protein levels after morphine treatment. Western blot results revealed that the Cdk5 protein level did not change after morphine treatment; however, the p35 protein level markedly increased (Fig. 4B). Accordingly, Cdk5 activity may be required for morphine antinociceptive tolerance.

Next, we investigated the role of DOR Thr-161 phosphorylation in morphine antinociceptive tolerance. In Western blot analyses of the DRG extracts, the phosphoselective pT161 DOR antibody recognized a protein of molecular mass $\sim 60 \mathrm{kDa}$ (Fig. $4 C$ ). The observed molecular mass is consistent with a glycosylated form of the rat DOR. Western blot analysis using the pT161 DOR antibody demonstrated a conspicuous increase in the DOR protein isolated from rat treated with morphine over DOR protein from untreated, control rat (Fig. 4C). If the receptor phosphorylation detected by the pT161 DOR antibody was responsible in morphine antinociceptive tolerance observed, then the preven- 
A

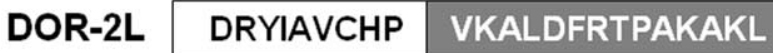

\section{Tat-DOR-2L RKKRRQRRR VKALDFRTPAKAKL Tat DOR-2L}

\section{\begin{tabular}{l|l|l} 
Tat-ctrl & RKKRRQRRR & RAAKVPKFLTLDKA \\
\hline
\end{tabular} Tat shuffled DOR-2L}

B
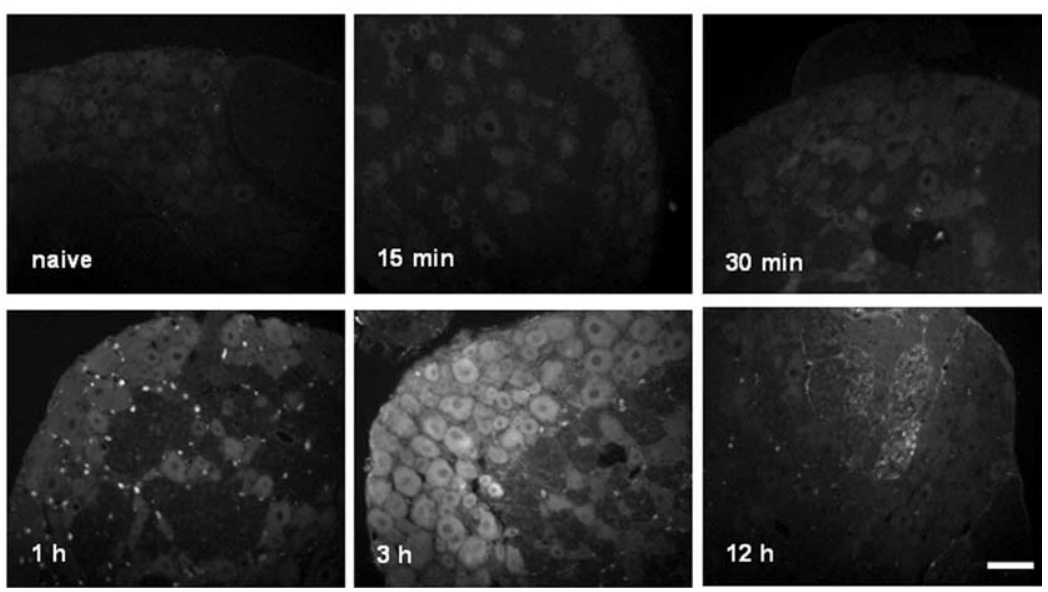

Figure 5. Construction and detection of Tat-DOR-2L. A, Schematic representation of the second intracellular loop of DOR (DOR-2L). The bold letters indicate the C-terminal $14 \mathrm{ad}$, including the TPAK sequence, which were fused to the HIV tat protein (RKKRRQRRR). A scrambled sequence of 14 aa was fused to Tat to serve as a control. $\boldsymbol{B}$, Time course of TAMRA-Tat-DOR-2L (10 $\mu \mathrm{g})$ fluorescence in rat DRG after intrathecal administration. The concentration of the peptide increased in a time-dependent manner and peaked at $60-180 \mathrm{~min}$ after injection. Scale bar, $20 \mu \mathrm{m}$.

tion of morphine antinociceptive tolerance by roscovitine (Fig. $1 A$ ) should be associated with dephosphorylation. To test this possibility, we next detected the level of pT161 DOR in DRG extracts of rats after morphine exposure with or without roscovitine pretreatment (Fig. 4D). These results indicated that the DOR was phosphorylated on threonine-161 in vivo, and its phosphorylation level increased during morphine antinociceptive tolerance, which further suggests that inhibition of the activity of Cdk5 could reduce the DOR Thr-161 phosphorylation level in vivo.

Considerable evidence has shown that DOR is essential for morphine antinociceptive tolerance (Abdelhamid et al., 1991; Kest et al., 1996; Zhu et al., 1999; Nitsche et al., 2002). Consistent with this idea, we found that mutation of the C $\mathrm{dk} 5$ phosphorylation site in DOR (Thr-161) resulted in low levels of cell surface expression and decreased phosphorylation levels. These results suggest that phosphorylation of Thr-161 is crucial for normal DOR function and is important in morphine antinociceptive tolerance.

To test this hypothesis, we delivered following plasmids (pEGFP-N3-WT-DOR, pEGFP-N3-T161A, and pEGFP-N3K164N) intrathecally using Lipofectamine. Lipofectamine 2000 has been used widely with nonviral plasmid vectors to transfer foreign genes into a variety of mammalian cell types, both dividing and nondividing (Yao et al., 2002; Wang et al., 2005; Yang et al., 2007). The primary sensory neurons showed stronger green fluorescence (Fig. $4 E$ ) than the control group, indicating successful gene delivery. At $4 \mathrm{~d}$ after gene delivery, all rats were given morphine ( $5 \mathrm{mg} / \mathrm{kg}$, s.c.) every $2 \mathrm{~h}$ for $12 \mathrm{~h}$ to induce an acute tolerance to morphine analgesia. Animals were tested for thermal response using the tail flick test at 30 min after every injection. Gene delivery did not alter the baseline tail flick latency (Fig. $4 F$ ).
DOR control rats showed morphine antinociceptive tolerance from the fourth injection onward. In contrast, the T161A and $\mathrm{K} 164 \mathrm{~N}$ groups did not develop any obvious morphine antinociceptive tolerance until the sixth injection (Fig. $4 G, H$ ), suggesting that T161A-DOR and K164NDOR can delay the development of morphine antinociceptive tolerance in vivo. The effect of K164N on the attenuation of morphine antinociceptive tolerance strengthens the conclusion that DOR phosphorylation at Thr-161 by Cdk5 plays a crucial role in morphine antinociceptive tolerance.

Tat fusion peptide of DOR-2L (TatDOR-2L) disrupts the cell surface expression and the formation of the DOR-MOR heterodimers

We showed that mutation at Thr-161 could disrupt the function of DOR and attenuate morphine antinociceptive tolerance in assays in which the mutant gene was delivered intrathecally. Hence, we hypothesized that the second intracellular loop of DOR, in which Thr-161 is located, may be a target for approaches seeking to attenuate morphine antinociceptive tolerance. To test this hypothesis, we created a peptide that contained 14 aa of DOR-2L, including the TPAK sequence, and we made it cell-permeable by fusing it to the HIV Tat protein (RKKRRQRRR), giving rise to the Tat-DOR-2L peptide. A scrambled 14 residue of the DOR-2L sequence peptide was fused to Tat and served as a control (Tat-ctrl) (Fig. 5A). Using fluorescently tagged peptides (TAMRA-Tat-DOR-2L), we detected their presence in DRG neurons after a single intrathecal injection $(10 \mu \mathrm{g})$. The concentration of peptide increased in a timedependent manner, peaking at 1 and $3 \mathrm{~h}$ after injection (Fig. 5B).

To investigate whether Tat-DOR-2L can perturb Cdk5-DOR complexes, we examined the effects of the peptide on the coimmunoprecipitation of Cdk5 with DOR. The protein fraction of rat DRG tissue was incubated with Tat-DOR-2L or with Tat-ctrl. Adding Tat-DOR-2L, but not Tat-ctrl, to the rat DRG extracts significantly reduced coimmunoprecipitation of Cdk5 with DOR, suggesting the existence of Cdk5-DOR complexes in rat DRG that can be effectively disrupted by the Tat-DOR-2L peptide (Fig. 6A).

To test whether Tat-DOR-2L peptide affects DOR Thr-161 phosphorylation, we applied Tat-DOR-2L to NG108-15 cells for $4 \mathrm{~h}$; we found that, compared with Tat-ctrl treatment, NG108-15 cells treated with Tat-DOR-2L showed a significant decrease in DOR Thr-161 phosphorylation (Fig. 6B). We also confirmed this effect of Tat-DOR-2L on endogenous DOR phosphorylation in cultured primary DRG neurons (Fig. 6C).

Because Tat-DOR-2L could inhibit DOR Thr-161 phosphorylation, next we tested whether the Tat-DOR-2L peptide can inhibit DOR cell surface expression. We observed reduction of DOR at the cell surface using Tat-DOR-2L ( $3 \mu \mathrm{g} / \mathrm{ml} ; 4 \mathrm{~h})$, but not Tat-ctrl in NG108-15 cells overexpressed GFP-DOR (Fig. 6D). We confirmed this effect of Tat-DOR-2L on endogenous DOR in cultured DRG neurons (Fig. 6E). Because Tat-DOR-2L can re- 
A

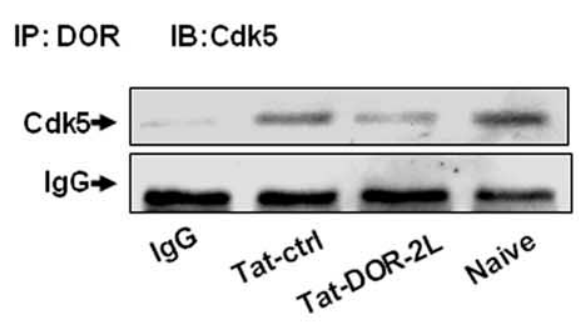

D
B

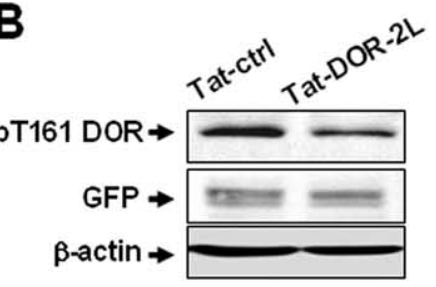

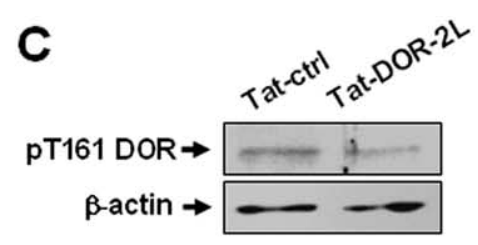

E

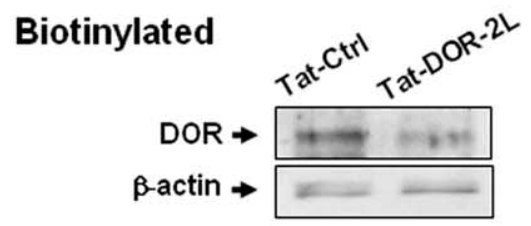

Total extract

Total extract

GFP-DOR $\rightarrow$
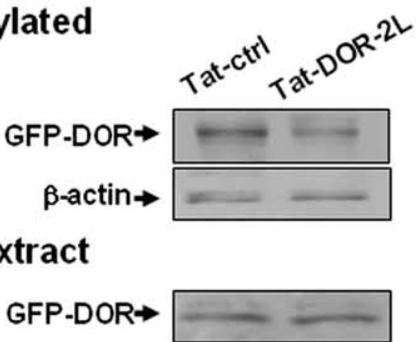

\section{Total extract}

$\mathrm{DOR} \rightarrow \square$
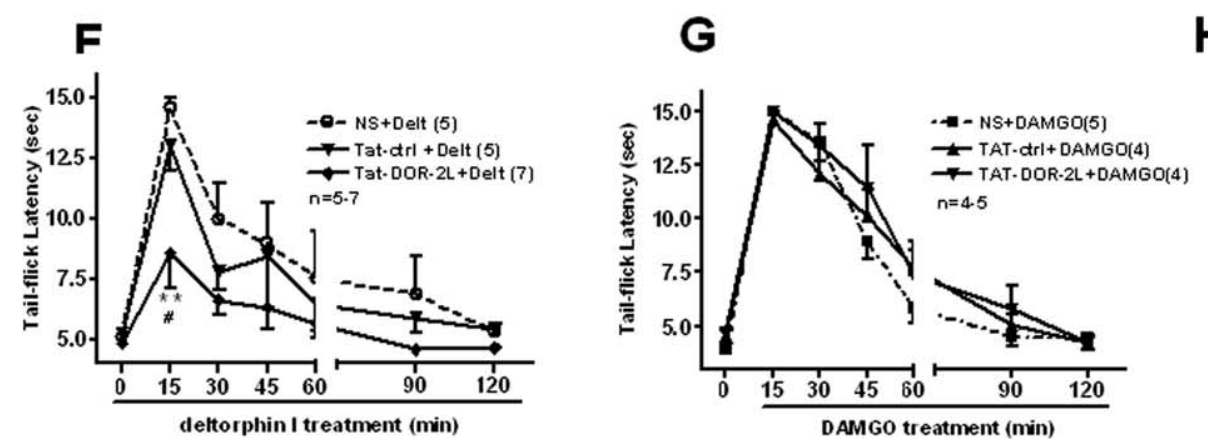

H

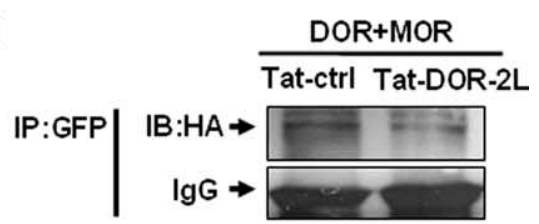

\begin{tabular}{l|l} 
Lys ate & $\mathrm{IB}: \mathrm{HA} \rightarrow \square$ \\
& $\mathrm{IB}: \mathrm{GFP} \rightarrow$
\end{tabular}

Figure 6. Tat-DOR-2L disrupts the coimmunoprecipitation of Cdk5 and DOR, the cell surface expression, and the formation of the DOR-MOR heterodimers. A, Reduced coimmunoprecipitation of Cdk5 and DOR after addition of Tat-DOR-2L, but not Tat-ctrl, into lysates before coimmunoprecipitation. B, Tat-DOR-2L reduces DOR Thr-161 phosphorylation. NG108-15 cells were transfected with GFP-DOR and treated for $4 \mathrm{~h}$ with the indicated drugs, and then immunoblotted with pT161 DOR antibody. Total cell lysates were immunoblotted with GFP and actin antibodies as a loading control. C, Tat-DOR-2L reduces DOR Thr-161 phosphorylation. Primary cultured DRG were treated for $4 \mathrm{~h}$ with the indicated drugs, and then immunoblotted with pT161 DOR antibody. Total cell lysates were immunoblotted with actin antibodies as loading controls. $\boldsymbol{D}, \boldsymbol{E}$, Cell surface biotinylation and Western blotting were performed in NG108-15 cells and primary cultured DRG neurons with indicated treatments to detect cell surface DOR level. D, Pretreatment of Tat-DOR-2L $(3 \mu \mathrm{g} / \mathrm{ml} ; 4 \mathrm{~h})$ decreased DOR cell surface expression in NG108-15 cells transfected with EGFP-DOR, compared with cells pretreated with Tat-ctrl. Total extract represents the total expression level. $\boldsymbol{E}$, Tat-DOR-2L pretreatment $(3 \mu \mathrm{g} / \mathrm{ml} ; 4 \mathrm{~h}$ ) decreased endogenous DOR cell surface expression in primary cultured DRG neurons compared with Tat-ctrl pretreatment. Total extract represents the total expression level. NT, Nontreatment. $\boldsymbol{F}$, Intrathecal pretreatment of Tat-DOR-2L ( $3 \mu \mathrm{g}$ ) for $30 \mathrm{~min}$ disrupted the antinociceptive effect induced by intrathecal injection of deltorphin I $(10 \mu \mathrm{g})$. Each point represents the mean, and vertical bars represent the SEM. ${ }^{* *} p<0.01$, compared with NS group; ${ }^{\#} p<0.05$, compared with Tat-ctrl group $(n=5-7)$. G, Intrathecal pretreatment with Tat-DOR-2L $(3 \mu \mathrm{g})$ for $30 \mathrm{~min}$ did not disrupt the antinociceptive effect induced by intrathecal injection of DAMGO (1 $\mathrm{nmol})$. Each point represents the mean, and vertical bar represents the SEM $(n=4-5)$. Data were analyzed by ANOVA, followed by the Newman-Keuls multiple-comparison test to test the difference between groups. $\boldsymbol{H}$, Cell lysates from NG108-15 cells cotransfected with EGFP-DOR $(2 \mu \mathrm{g})$, HA-MOR (4 $\mu \mathrm{g})$ CDNA were pretreated by Tat-DOR-2L/Tat-ctrl (3 $\mu \mathrm{g} / \mathrm{ml})$, and then were subjected to immunoprecipitation using polyclonal anti-GFP antibody, and associated HA-MOR was detected by immunoblotting using a monoclonal anti-HA antibody. Level of DOR and MOR under each transfection condition is shown by immunoblotting with anti-GFP and anti-HA antibody, respectively.

duce the availability of DOR located at the cell surface, the functional disturbance of DOR located at the cell surface by TatDOR-2L was further examined by studying DOR-mediated spinal analgesia. DOR in C-fiber terminals is known to be involved in analgesia at the level of the spinal cord (Labuz et al., 1998; Bilsky et al., 2000). Thus, we designed an experiment to test whether Tat-DOR-2L could disrupt the antinociceptive effect induced by intrathecal injection of a more specific DOR agonist deltorphin I instead of DPDPE, which we used in the NG108-15 cells, because both DOR and MOR express in DRG neurons. Rats were pretreated with NS, Tat-ctrl (3 $\mu \mathrm{g})$, or Tat-DOR-2L (3 $\mu \mathrm{g})$ $30 \mathrm{~min}$ before deltorphin I treatment $(10 \mu \mathrm{g})$. Tail flick latencies were then measured at different times after deltorphin I injection. In rats pretreated with NS or Tat-ctrl, deltorphin I caused a peak increase in tail flick latency at $15 \mathrm{~min}$, and this returned to the levels observed in the vehicle control after 40-60 min. However, in the rats pretreated with Tat-DOR-2L, the antinociceptive effect of deltorphin I was significantly attenuated compared with the deltorphin I plus Tat-ctrl group (Fig. 6F). Thus, DORmediated spinal analgesia was specifically impaired by Tat-DOR2L. To ensure that these changes were not mediated by MOR activation, we examined MOR-mediated spinal analgesia through intrathecal injection of DAMGO, the specific agonist of MOR. The antinociceptive effect of DAMGO was unchanged, indicating that Tat-DOR-2L did not affect MOR-mediated spinal analgesia (Fig. $6 G$ ) and that the specific target of Tat-DOR-2L is DOR rather than MOR.

As shown in Figure 3, the action of Cdk5 might be through 

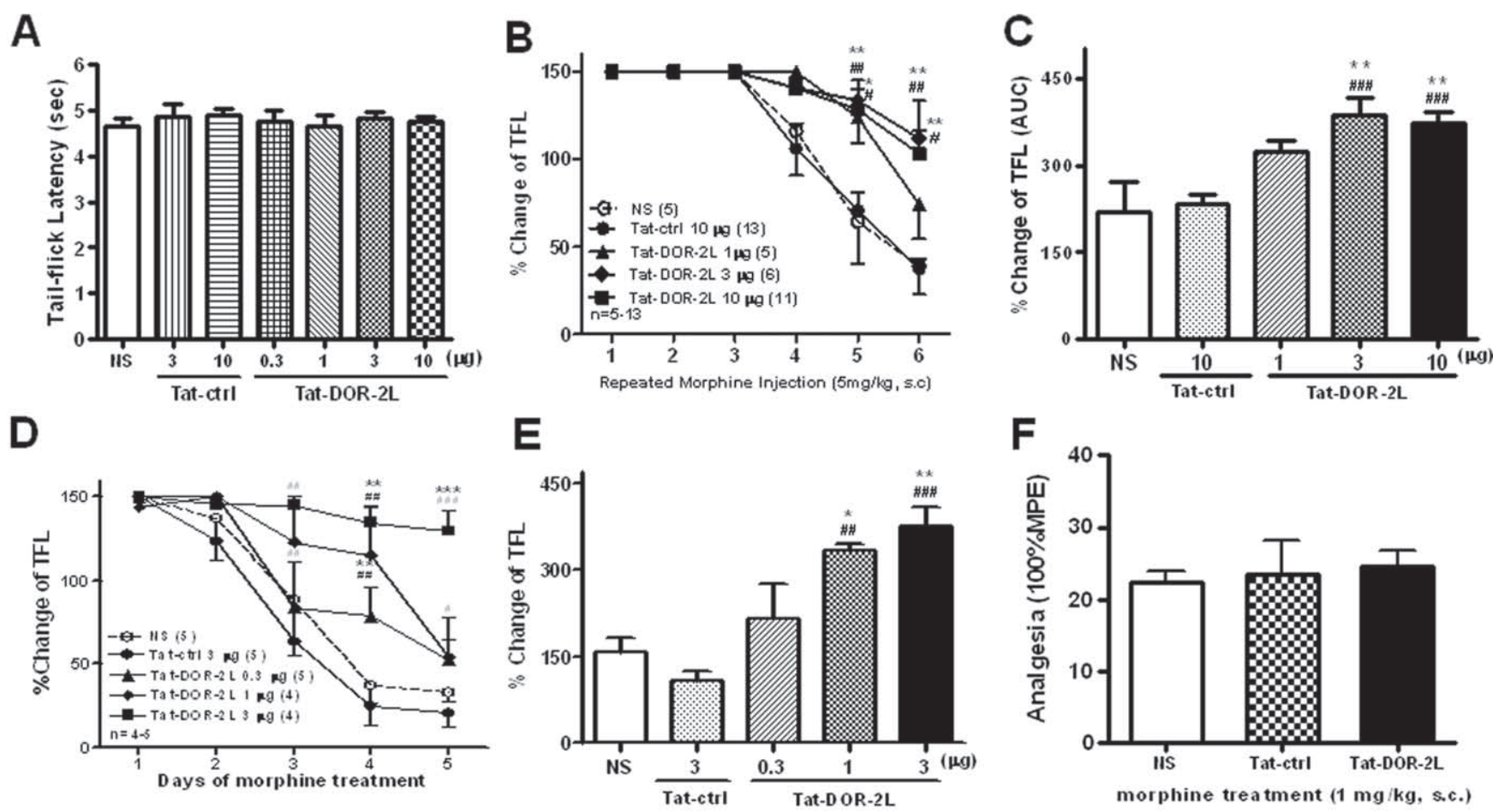

$\mathbf{G}$

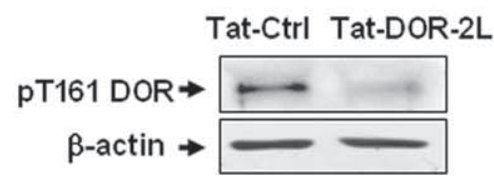

Figure 7. Administration of Tat-DOR-2L attenuates the development of morphine tolerance. $\boldsymbol{A}$, Intrathecal injection of Tat fusion peptide had no effect on the baseline tail flick latency. $\boldsymbol{B}$, Intrathecal pretreatment of Tat-DOR-2L for $30 \mathrm{~min}$ at $3 \mu \mathrm{g}$ and at $10 \mu \mathrm{g}$ caused profoundly slower development of morphine antinociceptive tolerance compared with Tat-ctrl or NS control groups, whereas the $1 \mu \mathrm{g}$ dose showed a weak effect. ${ }^{*} p<0.05,{ }^{* *} p<0.01$, compared with NS group; ${ }^{\#} p<0.05,{ }^{\# \#} p<0.01$, compared with Tat-ctrl group ( $n=5-13$ ). C, Area under the curve (AUC) of $\boldsymbol{B}$. AUC was calculated from the fourth morphine injection to the sixth morphine injection. ${ }^{* *} p<0.01$, compared with NS group; ${ }^{\# \# \# ~} p<0.001$, compared with Tat-ctrl group. $\boldsymbol{D}$, Intrathecal injections of Tat-DOR-2L ( 1 or $3 \mu \mathrm{g}$ ); both dosage groups developed morphine antinociceptive tolerance much more slowly than the Tat-ctrl and NS control groups, whereas the $0.3 \mu \mathrm{g}$ dose had no effect. ${ }^{* *} p<0.01,{ }^{* * *} p<0.001$, compared with NS group; ${ }^{*} p<0.05$, ${ }^{\# \#} p<0.01,{ }^{\# \#} p<0.001$, compared with the Tat-ctrl group $(n=4-5)$. All data were analyzed by ANOVA, followed by the Newman-Keuls multiple-comparison test. $\boldsymbol{E}$, AUC of $\boldsymbol{D}$. AUC was calculated from the third day to the fifth day. ${ }^{*} p<0.05,{ }^{* *} p<0.01$, compared with NS group; ${ }^{\# \#} p<0.01$, ${ }^{\# \# \#} p<0.001$, compared with Tat-ctrl group. Error bars indicate SEM. $\boldsymbol{F}$, Intrathecal pretreatment with Tat-DOR-2L ( $3 \mu \mathrm{g})$ for 30 min did not disrupt the antinociceptive effect induced by subcutaneous injection of morphine ( $1 \mathrm{mg} / \mathrm{kg}$, a dose that gives $20 \%$ maximal possible effect) $(n=4-5)$. G, Representative Western blot analysis of DRG protein isolated from rats treated with morphine repeatedly, pretreatment with Tat-DOR-2L or Tat-ctrl, blotted with PT161 DOR antibody. Total DRG lysates were immunoblotted with actin antibody as loading controls.

phosphorylation of DOR at Thr-161 to affect the formation of DOR-MOR heterodimers, suggesting that DOR-2L, which includes Thr-161, could be an important domain in the formation of DOR-MOR heterodimers. To further test this, we cotransfected NG108-15 cells with GFP-DOR and HA-MOR with or without Tat-DOR-2L ( $3 \mu \mathrm{g} / \mathrm{ml} ; 4 \mathrm{~h})$; the results show that interaction of MOR and DOR is indeed attenuated by Tat-DOR-2L (Fig. $6 H$ ).

Tat-DOR-2L delays the development of acute and chronic morphine antinociceptive tolerance

The above results indicate that Tat-DOR-2L can inhibit DOR function, as well as the interaction between Cdk5 and DOR. To determine whether Tat-DOR-2L can delay the development of morphine antinociceptive tolerance, similar to the results with intrathecal delivery of exogenous T161A-DOR and K164NDOR, we induced acute and chronic morphine antinociceptive tolerance. As mentioned above, all rats were given morphine (5 $\mathrm{mg} / \mathrm{kg}$, s.c.) every $2 \mathrm{~h}$ for $12 \mathrm{~h}$ to induce acute tolerance to morphine analgesia. Tat-DOR-2L and Tat-ctrl were dissolved in sa- line and injected intrathecally in different doses 30 min before the first morphine treatment. Animals were tested for thermal response using the tail flick test $30 \mathrm{~min}$ after every morphine injection. Intrathecal injection of the Tat fusion peptide did not alter either the baseline tail flick latency (Fig. 7A) or rat movement as detected by the inclined plane test (data not shown). Intrathecal injection of Tat-DOR-2L at 3 and $10 \mu \mathrm{g}$ significantly reduced the rate of morphine tolerance development compared with the saline (NS) and Tat-ctrl groups, whereas a relatively weak effect was observed for the $1 \mu \mathrm{g}$ group (Fig. $7 \mathrm{~B}, \mathrm{C}$ ). The above results suggest that intrathecal administration of Tat-DOR-2L can delay the development of acute morphine antinociceptive tolerance. Therefore, we examined whether Tat-DOR-2L can produce similar behavioral effects on chronic morphine tolerance. Morphine or NS was injected subcutaneously at $5 \mathrm{mg} / \mathrm{kg}$ twice a day, and Tat-DOR-2L or Tat-ctrl were given once a day intrathecally 30 min before the first morphine injection. Animals were tested for thermal response using the tail flick test $30 \mathrm{~min}$ after the first morphine injection each day. These rats showed reduced pain in the initial phase of morphine treatment, but developed tolerance 
from the second day onward. Figure 7, $D$ and $E$, shows that TatDOR-2L can delay the development of chronic antinociceptive morphine antinociceptive tolerance, similar to its effects on acute morphine tolerance. Next, we found that the analgesia induced by a submaximal dose of morphine $(1 \mathrm{mg} / \mathrm{kg}$ ) was not changed by intrathecal injection of Tat-DOR-2L, suggesting that the effect of Tat-DOR-2L was not the result of a change in morphine-induced analgesia (Fig. $7 F$ ). As mentioned above, we observed a significant increase of DOR Thr-161 phosphorylation level after morphine antinociceptive tolerance, whereas Tat-DOR-2L could lower the DOR Thr-161 phosphorylation level in vivo during morphine antinociceptive tolerance (Fig. 7G). These results indicated that Tat-DOR-2L delayed morphine antinociceptive tolerance might be through inhibiting DOR Thr-161 phosphorylation level.

\section{Discussion}

In summary, the present study demonstrates that Cdk5 acts as a crucial kinase in the nervous system and that it has the potential to phosphorylate Thr-161 in the second intracellular loop of DOR, but not of MOR. Lys-164 in the second loop of DOR is necessary for phosphorylation by Cdk5. There are $\sim 20$ phosphorylation sites on various serine, threonine, and tyrosine residues on the opioid receptor in regions conceivably accessible to protein kinases. Indeed, phosphorylation of opioid receptors is the first step in opioid receptor activation during such processes as desensitization and trafficking. As a classical G-proteincoupled receptor (GPCR), the phosphorylation status of opioid receptor could be divided into two categories: basal (constitutive) phosphorylation and agonist-induced phosphorylation. The protein kinases responsible for agonist-induced phosphorylation of DOR have been investigated extensively, including second messenger-dependent protein kinases [PKC (protein kinase C), PKA (cAMP-dependent protein kinase), CaMKII $\left(\mathrm{Ca}^{2+} /\right.$ calmodulin-dependent protein kinase II), GRKs (G-proteincoupled receptor kinases), and MAPKs (mitogen-activated protein kinases)], all of which play important roles in the regulation of opioid signal transduction (Liu and Anand, 2001). However, information about the kinases responsible for agonistindependent phosphorylation or the role of constitutive phosphorylation in modulating DOR function is limited (Johnson et al., 2005).

Recently, Pareek and Kulkarni (2006) reported that hyperactivation of Cdk5 is an important factor in the development of tolerance, but the mechanism of regulation of morphine antinociceptive tolerance by Cdk5 is unclear. Here, we report, for the first time, that Cdk5-mediated DOR phosphorylation occurs at Thr-161, which is located in a typical Cdk 5 consensus sequence (T/SPXK/H/R). We also show that Lys-164 is necessary for phosphorylation by Cdk 5 and that both inhibition of Cdk5 and mutation of Thr-161 can attenuate the basal phosphorylation level of DOR and significantly decrease the amount of functional DOR at the cell surface. Therefore, direct phosphorylation of DOR by Cdk5 is very likely, although we cannot exclude the possibility of phosphorylation of this site in DOR by other protein kinases. Phosphorylation of NR2B at Ser-1480 has been proposed to disrupt the interaction of NMDA receptors (NMDARs) with the PDZ (postsynaptic density-95/Discs large/zona occludens-1) domains of PSD-95 (postsynaptic density-95) and SAP102 (synapse-associated protein with a molecular weight of $102 \mathrm{kDa}$ ), and reduce surface NMDAR expression (Chung et al., 2004). Phosphorylation of some Ser/Thr residues in the C-terminal domain of MOR may act as a signal to reduce receptor trafficking (El
Kouhen et al., 2001). We suggest that Cdk5 may regulate membrane trafficking of DOR through phosphorylation at Thr-161, but the mechanisms involved still need to be studied intensively.

The mechanisms underlying opiate tolerance are not fully understood, but appear to involve numerous and complex physiological adaptations. The present study indicates that mutation of DOR at Thr-161 impairs acute morphine antinociceptive tolerance in vivo. This process may be regulated by Cdk5, because mutation of DOR at Lys-164 to prevent phosphorylation by Cdk 5 impairs acute morphine antinociceptive tolerance in vivo. The present morphine antinociceptive tolerance measurements clearly indicate that overexpression of these mutants (T161A and $\mathrm{K} 164 \mathrm{~N}$ ) in rats can attenuate the development of morphine antinociceptive tolerance by inhibiting the function of DOR. DOR has been conclusively shown to be involved in morphine antinociceptive tolerance (Abdelhamid et al., 1991; Kest et al., 1996; Hepburn et al., 1997; Zhu et al., 1999; Riba et al., 2002). In support of this idea, many studies find that blockade of DOR attenuates morphine antinociceptive tolerance (Abdelhamid et al., 1991; Fundytus et al., 1995; Kest et al., 1996; Zhu et al., 1999; Roy et al., 2005). Activation of DOR appears to be important in the mechanisms of morphine antinociceptive tolerance. In fact, it represents an important intermediate step in the development of morphine antinociceptive tolerance. Consistent with the idea of increased receptor function, prolonged morphine treatment targets DOR to neuronal plasma membranes (Cahill et al., 2001; Morinville et al., 2003, 2004), preprotachykinin A gene knockout mice (that leads to reduced cell surface insertion of DOR) do not develop morphine tolerance (Guan et al., 2005). Constitutive receptor activity has been proposed to increase in animals treated chronically with morphine. Chronic morphine treatment induces the translocation of DOR from intracellular compartments to neuronal plasma membranes, thereby enhancing the number of functional, bioavailable receptors (Cahill et al., 2007). The changes in DOR functional competence after chronic morphine were dependent on selective stimulation of the MOR and not through direct interaction of morphine with DOR or other targets, because both targeting and changes in DOR signaling were absent in MOR-null mutant mice (Morinville et al., 2003). Recently, a role for the heterodimerization of $\mu$ - and $\delta$-opioid receptors in the development of morphine antinociceptive tolerance has been proposed (Rozenfeld et al., 2007). This is supported by the finding that MOR and DOR are coexpressed in the same cells in the DRG (Fields et al., 1980; Egan and North, 1981), and in axonal terminals of the superficial dorsal horn (Arvidsson et al., 1995). Mounting evidence indicates that MOR and DOR form heterodimers in vitro and in vivo (George et al., 2000; Gomes et al., 2000, 2004). A requirement of DOR-MOR heterodimers in the development of morphine tolerance is also supported by the findings in many studies that morphine antinociceptive tolerance was not shown by animals that did not express DOR or in which DOR insertion in the cell membrane was impaired. The fact that chronic morphine treatment increases DOR surface insertion suggests that morphine tolerance correlates with the formation of DOR-MOR heterodimers.

We report here, for the first time, that $\mathrm{Cdk} 5$ can accelerate morphine antinociceptive tolerance by phosphorylating Thr-161 of DOR and that inhibition of this phosphorylation may disrupt the function of DOR by decreasing its surface expression. We also observed that inhibition of $\mathrm{Cdk} 5$ can reduce the formation of DOR-MOR heterodimers; therefore, the role of CDK5 in modulating morphine antinociceptive tolerance could be attributable to its participation in decreased DOR cell surface bioavailability 
MOR-DOR heterodimer function. However, whether the decreased cell surface expression leads directly to the reduction of the formation of DOR-MOR heterodimers requires additional investigation.

The trafficking of many GPCRs, including DOR, has been linked to a large number of putative phosphorylation sites for many protein kinases or binding sites for regulatory proteins in the C-terminal tail (Sternini et al., 1996; Trapaidze et al., 1996; Cvejic and Devi, 1997). Our findings indicate that, in addition to the C-terminal tail, Thr-161 of the second intracellular loop domain of DOR is required for trafficking and morphine antinociceptive tolerance. No previous studies have shown any effect of Thr-161 mutation in DOR, except that Lowe et al. (2002) reported that mutation of Thr-161 in DOR significantly inhibited its fast desensitization in Xenopus oocytes. However, this differs from our results showing that mutation of DOR at Thr-161 significantly decreased the amount of functional DOR at the cell surface, whereas the overall amount of DOR at the surface did not change. The discrepancy may be explained by the following two reasons: (1) opioid receptors are not internalized in the Xenopus oocyte expression system; (2) neuronal cells (NG108-15 and DRG) and non-neuronal cells (Xenopus oocytes) have different levels of Cdk5 kinase activity.

With most of their sequence variation in their C-terminal tails, MOR and DOR show nearly complete sequence identity in the putative second intracellular loop, except for residues 163 and 164. Despite this remarkable sequence homology, MOR and DOR are apparently regulated very differently. The physiological significance of such differential regulation of phosphorylation, desensitization, and trafficking of these two closely related receptors remains to be elucidated. Nevertheless, we speculate that Cdk5 may contribute to the differential regulation through Thr161, the enzyme may directly phosphorylate Thr-161 of DOR, but not of MOR.

A crucial question to address is whether these basic findings can be applied to develop new therapeutic approaches for the prevention of morphine antinociceptive tolerance. Previous studies have focused on developing drugs or drug administration strategies that target receptors. Pharmacological blockade of NMDAR1 (Wong et al., 1996; Shimoyama et al., 2005), AMPAR (McLemore et al., 1997), and especially the DOR can attenuate morphine tolerance to some degree, but the nonspecific compounds involved may also induce undesirable side effects. After establishing that Cdk5 can phosphorylate Thr-161 in the second intracellular loop of DOR, we selected a 14 residue peptide from DOR containing the Cdk5 interaction domain and fused it to the HIV type I protein (Tat) to allow cell entry. We found that this Tat fusion peptide (Tat-DOR-2L) could disrupt the interaction between Cdk5 and DOR and block antinociception mediated by spinally administered deltorphin I, a selective DOR agonist. Similar to the Thr-161 mutation, Tat-DOR-2L can reduce the cell surface expression of DOR and reduce the formation of DORMOR heterodimers through competitive inhibition. These results suggest that Tat-DOR-2L can antagonize the physiological function of DOR, thus delaying the development of acute and chronic morphine antinociceptive tolerance. The data also confirm that Thr-161, the putative phosphorylation site of $\mathrm{Cdk} 5$, plays an important role in the normal physiological function of DOR.

As mentioned above, MOR and DOR share nearly complete sequence identity in the putative second intracellular loop, except for residues 163 and 164. It is possible that Tat-DOR-2L can antagonize the function of DOR, but not MOR, and that this property of Tat-DOR-2L may prove a useful tool for studying how exactly DOR is involved in morphine antinociceptive tolerance.

This finding implies that drugs targeting Cdk5-regulated phosphorylation of DOR may accelerate the development of morphine antinociceptive tolerance. Coadministration of morphine and Tat-DOR-2L may provide a more suitable therapeutic approach than using morphine alone for pain relief. The potential therapeutic advantages of the Tat-DOR-2L peptide must be further explored; future studies will address other potential benefits of this peptide.

\section{References}

Abdelhamid EE, Sultana M, Portoghese PS, Takemori AE (1991) Selective blockage of delta opioid receptors prevents the development of morphine tolerance and dependence in mice. J Pharmacol Exp Ther 258:299-303.

Arvidsson U, Dado RJ, Riedl M, Lee JH, Law PY, Loh HH, Elde R, Wessendorf MW (1995) $\delta$-Opioid receptor immunoreactivity: distribution in brainstem and spinal cord, and relationship to biogenic amines and enkephalin. J Neurosci 15:1215-1235.

Beaudette KN, Lew J, Wang JH (1993) Substrate specificity characterization of a cdc2-like protein kinase purified from bovine brain. J Biol Chem 268:20825-20830.

Bilsky EJ, Qian X, Hruby VJ, Porreca F (2000) Antinociceptive activity of [beta-methyl-2',6'-dimethyltyrosine(1)]-substituted cyclic [D-Pen(2), D-Pen(5)] Enkephalin and [D-Ala(2),Asp(4)]-Deltorphin analogs. J Pharmacol Exp Ther 293:151-158.

Cahill CM, Morinville A, Lee MC, Vincent JP, Collier B, Beaudet A (2001) Prolonged morphine treatment targets $\delta$ opioid receptors to neuronal plasma membranes and enhances $\delta$-mediated antinociception. J Neurosci 21:7598-7607.

Cahill CM, Holdridge SV, Morinville A (2007) Trafficking of $\delta$-opioid receptors and other G-protein-coupled receptors: implications for pain and analgesia. Trends Pharmacol Sci 28:23-31.

Chung HJ, Huang YH, Lau LF, Huganir RL (2004) Regulation of the NMDA receptor complex and trafficking by activity-dependent phosphorylation of the NR2B subunit PDZ ligand. J Neurosci 24:10248-10259.

Cvejic S, Devi LA (1997) Dimerization of the $\delta$ opioid receptor: implication for a role in receptor internalization. J Biol Chem 272:26959-26964.

Egan TM, North RA (1981) Both mu and delta opiate receptors exist on the same neuron. Science 214:923-924.

El Kouhen R, Burd AL, Erickson-Herbrandson LJ, Chang CY, Law PY, Loh HH (2001) Phosphorylation of Ser 363, Thr 370 and Ser 375 residues within the carboxyl tail differentially regulates $\mu$-opioid receptor internalization. J Biol Chem 276:12774-12780.

Fields HL, Emson PC, Leigh BK, Gilbert RF, Iversen LL (1980) Multiple opiate receptor sites on primary afferent fibres. Nature 284:351-353.

Fundytus ME, Schiller PW, Shapiro M, Weltrowska G, Coderre TJ (1995) Attenuation of morphine tolerance and dependence with the highly selective $\delta$-opioid receptor antagonist $\operatorname{TIPP}[\psi]$. Eur J Pharmacol 286:105-108.

George SR, Fan T, Xie Z, Tse R, Tam V, Varghese G, O’Dowd BF (2000) Oligomerization of mu- and delta-opioid receptors. Generation of novel functional properties. J Biol Chem 275:26128-26135.

Gomes I, Jordan BA, Gupta A, Trapaidze N, Nagy V, Devi LA (2000) Heterodimerization of $\mu$ and $\delta$ opioid receptors: a role in opiate synergy. J Neurosci 20:RC110(1-5).

Gomes I, Gupta A, Filipovska J, Szeto HH, Pintar JE, Devi LA (2004) A role for heterodimerization of $\mathrm{mu}$ and delta opiate receptors in enhancing morphine analgesia. Proc Natl Acad Sci U S A 101:5135-5139.

Guan JS, Xu ZZ, Gao H, He SQ, Ma GQ, Sun T, Wang LH, Zhang ZN, Lena I, Kitchen I, Elde R, Zimmer A, He C, Pei G, Bao L, Zhang X (2005) Interaction with vesicle luminal protachykinin regulates surface expression of delta-opioid receptors and opioid analgesia. Cell 122:619-631.

Hepburn MJ, Little PJ, Gingras J, Kuhn CM (1997) Differential effects of NTI on morphine-induced tolerance and physical dependence in rats. J Pharmacol Exp Ther 281:1350-1356.

Jin W, Lee NM, Loh HH, Thayer SA (1994) Opioids mobilize calcium from inositol 1,4,5-trisphosphate-sensitive stores in NG108-15 cells. J Neurosci 14:1920-1929.

Johnson EE, Christie MJ, Connor M (2005) The role of opioid receptor 
phosphorylation and trafficking in adaptations to persistent opioid treatment. Neurosignals 14:290-302.

Kest B, Lee CE, McLemore GL, Inturrisi CE (1996) An antisense oligodeoxynucleotide to the delta opioid receptor (DOR-1) inhibits morphine tolerance and acute dependence in mice. Brain Res Bull 39:185-188.

Labuz D, Toth G, Machelska H, Przewlocka B, Borsodi A, Przewłocki R (1998) Antinociceptive effects of isoleucine derivatives of deltorphin I and deltorphin II in rat spinal cord: a search for selectivity of delta receptor subtypes. Neuropeptides 32:511-517.

Liu JG, Anand KJ (2001) Protein kinases modulate the cellular adaptations associated with opioid tolerance and dependence. Brain Res Rev 38:1-19.

Lowe JD, Celver JP, Gurevich VV, Chavkin C (2002) Mu-opioid receptors desensitize less rapidly than delta-opioid receptors due to less efficient activation of arrestin. J Biol Chem 277:15729-15735.

Matthes HW, Maldonado R, Simonin F, Valverde O, Slowe S, Kitchen I, Befort K, Dierich A, Le Meur M, Dollé P, Tzavara E, Hanoune J, Roques BP, Kieffer BL (1996) Loss of morphine-induced analgesia, reward effect and withdrawal symptoms in mice lacking the mu-opioid-receptor gene. Nature 383:819-823.

McLemore GL, Kest B, Inturrisi CE (1997) The effects of LY293558, an AMPA receptor antagonist, on acute and chronic morphine dependence. Brain Res 778:120-126.

Morinville A, Cahill CM, Esdaile MJ, Aibak H, Collier B, Kieffer BL, Beaudet A (2003) Regulation of $\delta$-opioid receptor trafficking via $\mu$-opioid receptor stimulation: evidence from $\mu$-opioid receptor knock-out mice. J Neurosci 23:4888-4898.

Morinville A, Cahill CM, Aibak H, Rymar VV, Pradhan A, Hoffert C, Mennicken F, Stroh T, Sadikot AF, O'Donnell D, Clarke PB, Collier B, Henry JL, Vincent JP, Beaudet A (2004) Morphine-induced changes in $\delta$ opioid receptor trafficking are linked to somatosensory processing in the rat spinal cord. J Neurosci 24:5549-5559.

Nikolic M, Dudek H, Kwon YT, Ramos YF, Tsai LH (1996) The cdk5/p35 kinase is essential for neurite outgrowth during neuronal differentiation. Genes Dev 10:816-825.

Nikolic M, Chou MM, Lu W, Mayer BJ, Tsai LH (1998) The p35/Cdk5 kinase is a neuron-specific Rac effector that inhibits Pakl activity. Nature 395:194-198.

Nitsche JF, Schuller AG, King MA, Zengh M, Pasternak GW, Pintar JE (2002) Genetic dissociation of opiate tolerance and physical dependence in $\delta$-opioid receptor-1 and preproenkephalin knock-out mice. J Neurosci 22:10906-10913.

Pareek TK, Kulkarni AB (2006) Cdk5: a new player in pain signaling. Cell Cycle 5:585-588.

Pareek TK, Keller J, Kesavapany S, Pant HC, Iadarola MJ, Brady RO, Kulkarni AB (2006) Cyclin-dependent kinase 5 activity regulates pain signaling. Proc Natl Acad Sci U S A 103:791-796.

Prado WA (2003) Antinociceptive potency of intrathecal morphine in the rat tail flick test: a comparative study using acute lumbar catheter in rats with or without a chronic atlanto-occipital catheter. J Neurosci Methods 129:33-39.

Riba P, Ben Y, Smith AP, Furst S, Lee NM (2002) Morphine tolerance in spinal cord is due to interaction between mu- and delta-receptors. J Pharmacol Exp Ther 300:265-272.

Roy S, Guo X, Kelschenbach J, Liu Y, Loh HH (2005) In vivo activation of a mutant $\mu$-opioid receptor by naltrexone produces a potent analgesic effect but no tolerance: role of $\mu$-receptor activation and $\delta$-receptor blockade in morphine tolerance. J Neurosci 25:3229-3233.
Rozenfeld R, Devi LA (2007) Receptor heterodimerization leads to a switch in signaling: $\beta$-arrestin2-mediated ERK activation by $\mu$ - $\delta$ opioid receptor heterodimers. FASEB J 21:2455-2465.

Rozenfeld R, Abul-Husn NS, Gomez I, Devi LA (2007) An emerging role for the delta opioid receptor in the regulation of mu opioid receptor function. ScientificWorldJournal 7:64-73.

Schulz R, Wehmeyer A, Schulz K (2002) Opioid receptor types selectively cointernalize with $\mathrm{G}$ protein-coupled receptor kinases 2 and 3. J Pharmacol Exp Ther 300:376-384.

Shimoyama N, Shimoyama M, Davis AM, Monaghan DT, Inturrisi CE (2005) An antisense oligonucleotide to the $N$-methyl-D-aspartate (NMDA) subunit NMDAR1 attenuates NMDA-induced nociception, hyperalgesia, and morphine tolerance. J Pharmacol Exp Ther 312:834-840.

Smart D, Lambert DG (1996) Delta-opioids stimulate inositol 1,4,5trisphosphate formation, and so mobilize $\mathrm{Ca}^{2+}$ from intracellular stores, in undifferentiated NG108-15 cells. J Neurochem 66:1462-1467.

Songyang Z, Lu KP, Kwon YT, Tsai LH, Filhol O, Cochet C, Brickey DA, Soderling TR, Bartleson C, Graves DJ, DeMaggio AJ, Hoekstra MF, Blenis J, Hunter T, Cantley LC (1996) A structural basis for substrate specificities of protein Ser/Thr kinases: primary sequence preference of casein kinases I and II, NIMA, phosphorylase kinase, calmodulin-dependent kinase II, CDK5, and erk1. Mol Cell Biol 16:6486-6493.

Sternini C, Spann M, Anton B, Keith DE Jr, Bunnett NW, von Zastrow M, Evans C, Brecha NC (1996) Agonist-selective endocytosis of mu opioid receptor by neurons in vivo. Proc Natl Acad Sci U S A 93:9241-9246.

Størkson RV, Kjørsvik A, Tjølsen A, Hole K (1996) Lumbar catheterization of the spinal subarachnoid space in the rat. J Neurosci Methods 65:167-172.

Trapaidze N, Keith DE, Cvejic S, Evans CJ, Devi LA (1996) Sequestration of the delta opioid receptor. Role of the C terminus in agonist-mediated internalization. J Biol Chem 271:29279-29285.

Tsai LH, Delalle I, Caviness VS Jr, Chae T, Harlow E (1994) p35 is a neuralspecific regulatory subunit of cyclin-dependent kinase 5. Nature 371:419-423.

Wang X, Wang C, Zeng J, Xu X, Hwang PY, Yee WC, Ng YK, Wang S (2005) Gene transfer to dorsal root ganglia by intrathecal injection: effects on regeneration of peripheral nerves. Mol Ther 2:314-320.

Wong CS, Cherng CH, Luk HN, Ho ST, Tung CS (1996) Effects of NMDA receptor antagonists on inhibition of morphine tolerance in rats: binding at mu-opioid receptors. Eur J Pharmacol 297:27-33.

Yang YR, He Y, Zhang Y, Li Y, Li Y, Han Y, Zhu H, Wang Y (2007) Activation of cyclin-dependent kinase 5 (Cdk5) in primary sensory and dorsal horn neurons by peripheral inflammation contributes to heat hyperalgesia. Pain 127:109-120.

Yao MZ, Gu JF, Wang JH, Sun LY, Lang MF, Liu J, Zhao ZQ, Liu XY (2002) Interleukin-2 gene therapy of chronic neuropathic pain. Neuroscience 112:409-416.

Zhang X, Bao L, Arvidsson U, Elde R, Hökfelt T (1998) Localization and regulation of the delta-opioid receptor in dorsal root ganglia and spinal cord of the rat and monkey: evidence for association with the membrane of large dense-core vesicles. Neuroscience 82:1225-1242.

Zhu Y, Hsu MS, Pintar JE (1998) Developmental expression of the $\mu, \kappa$, and $\delta$ opioid receptor mRNAs in mouse. J Neurosci 18:2538-2549.

Zhu Y, King MA, Schuller AG, Nitsche JF, Reidl M, Elde RP, Unterwald E, Pasternak GW, Pintar JE (1999) Retention of supraspinal $\delta$-like analgesia and loss of morphine tolerance in $\delta$ opioid receptor knockout mice. Neuron 24:243-252. 